\title{
Simulation of Brain Death from Fulminant De-efferentation
}

\author{
Yael Friedman, Liesly Lee, John R. Wherrett, Peter Ashby, Stirling Carpenter
} \begin{abstract}
secondary axonal degeneration, a primary axonopathy can also lead to a similar clinical presentation.
\end{abstract}

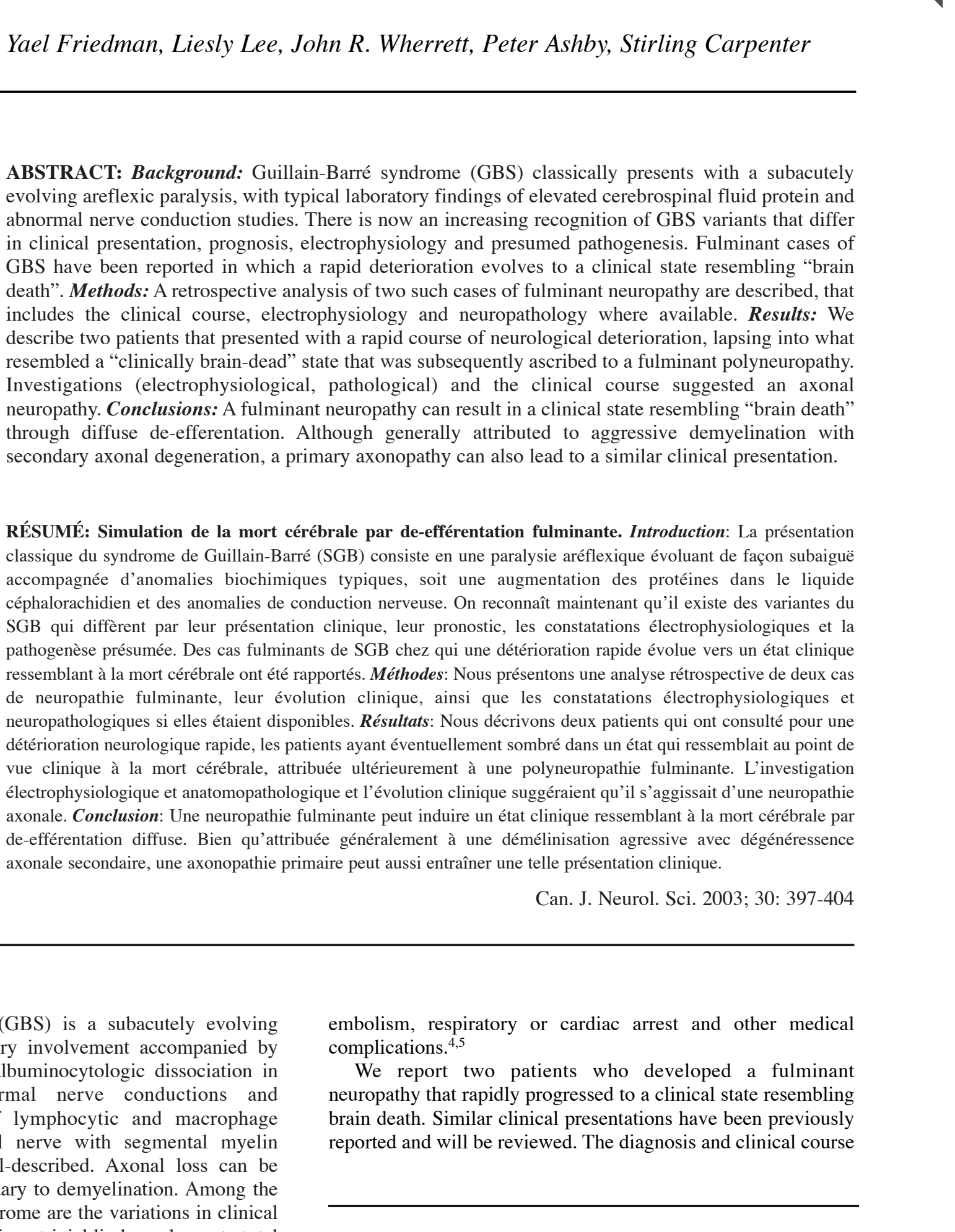

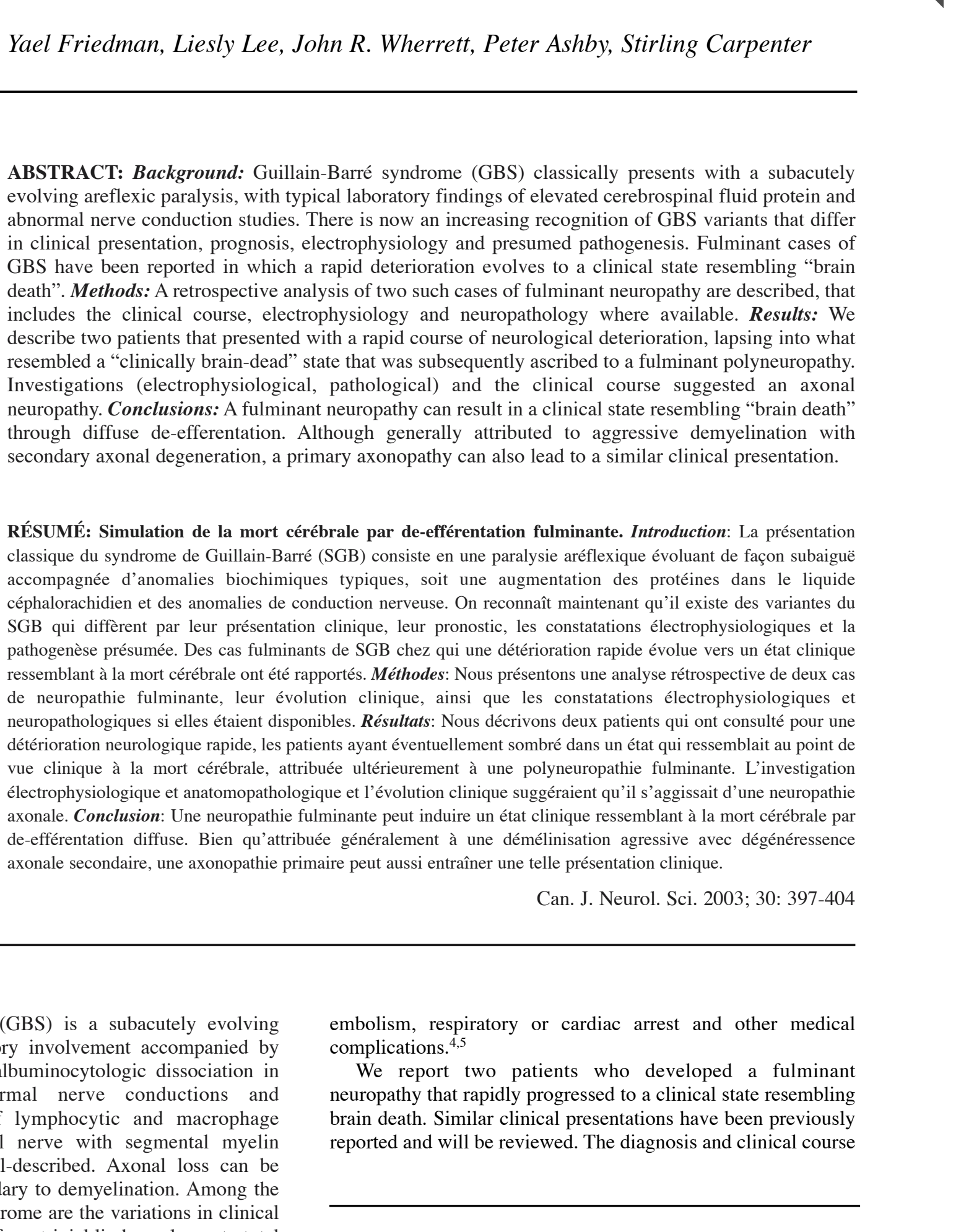

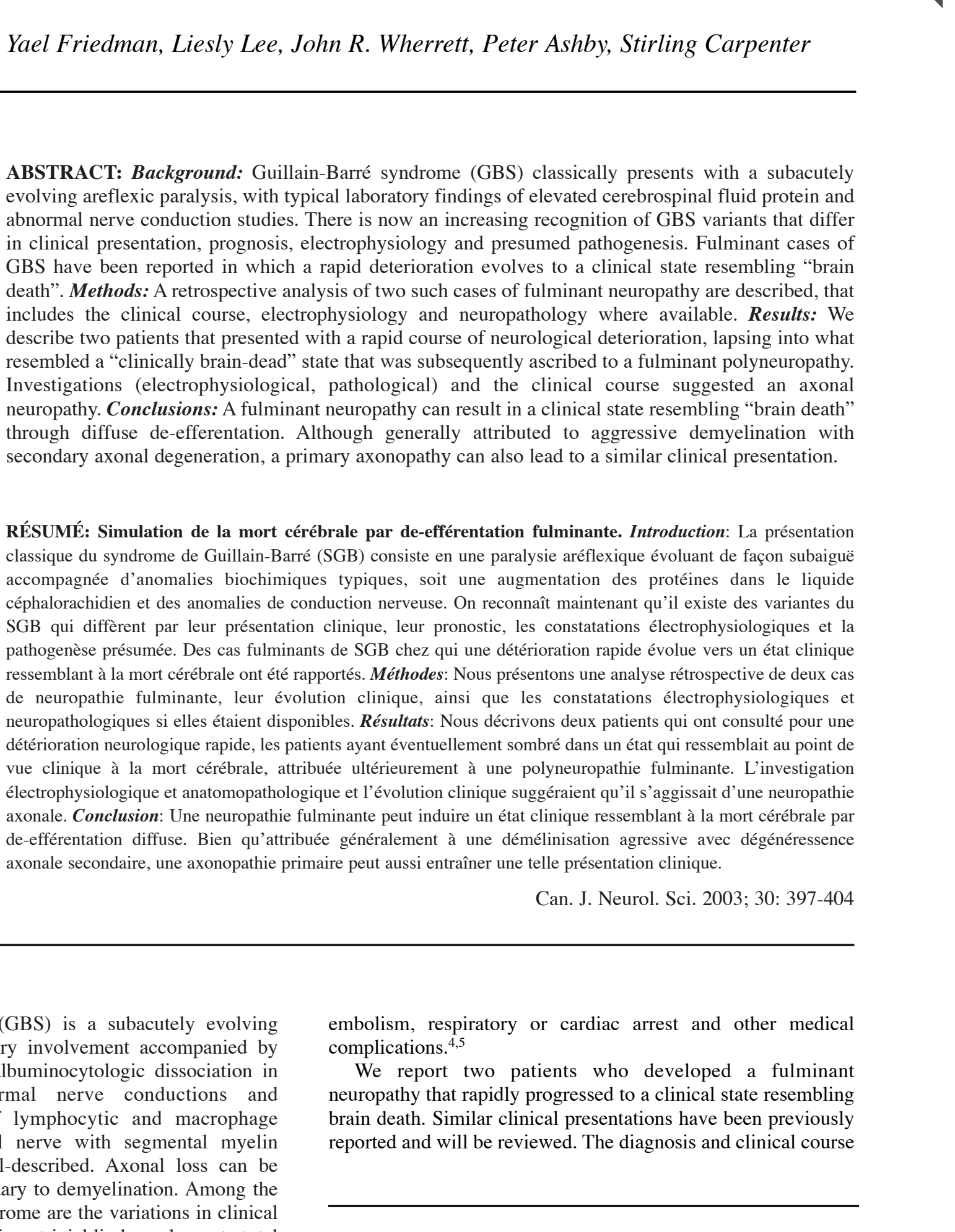

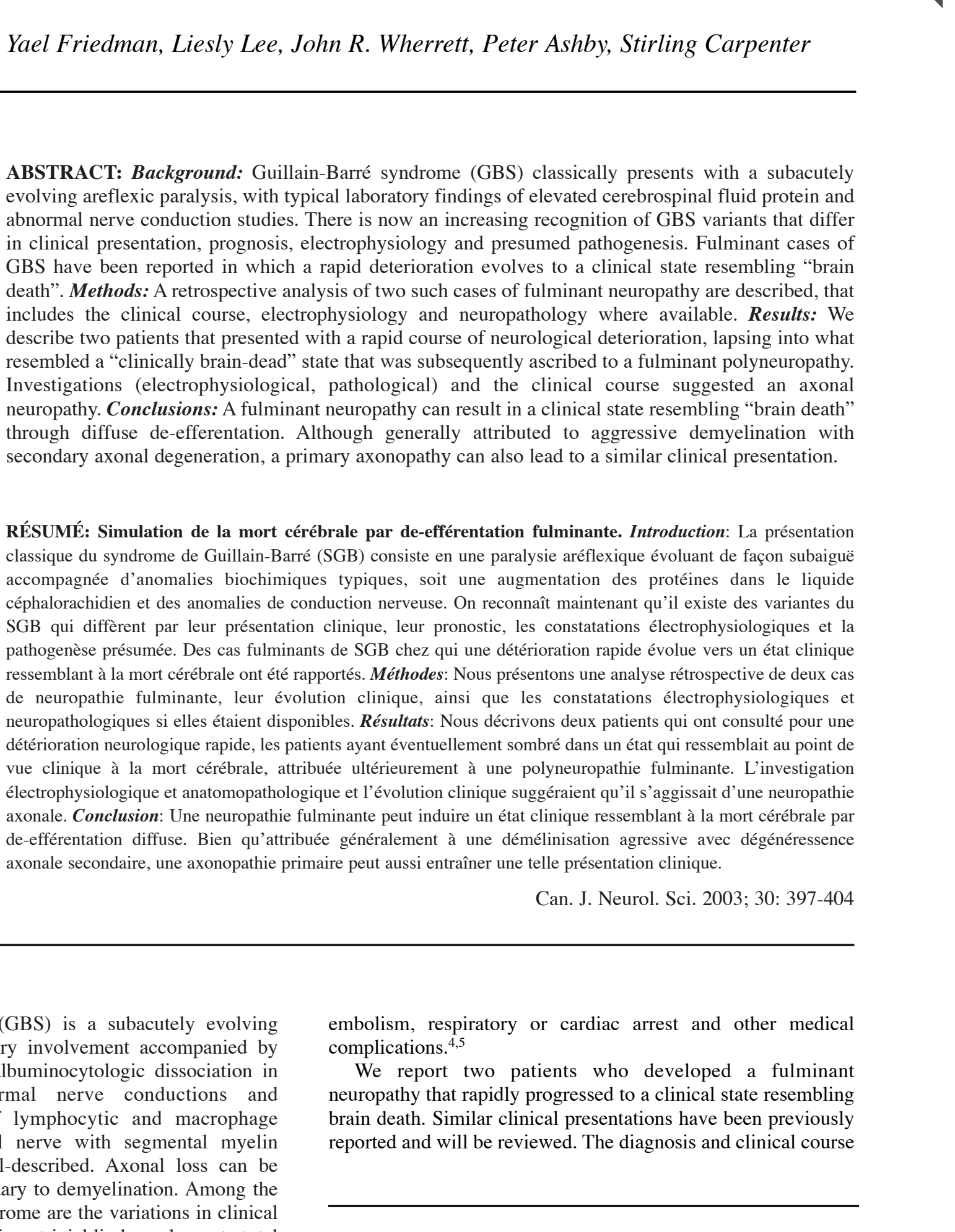

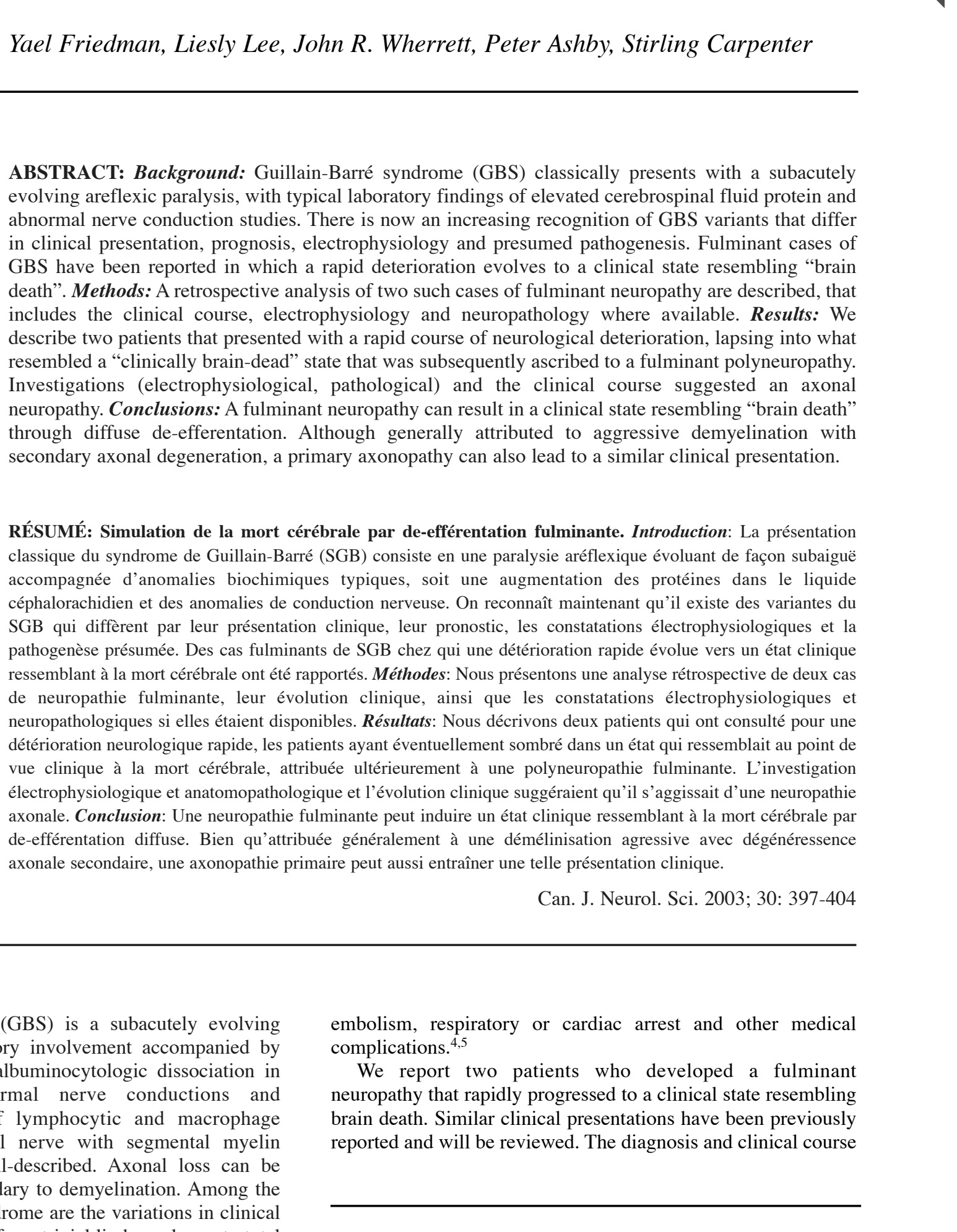

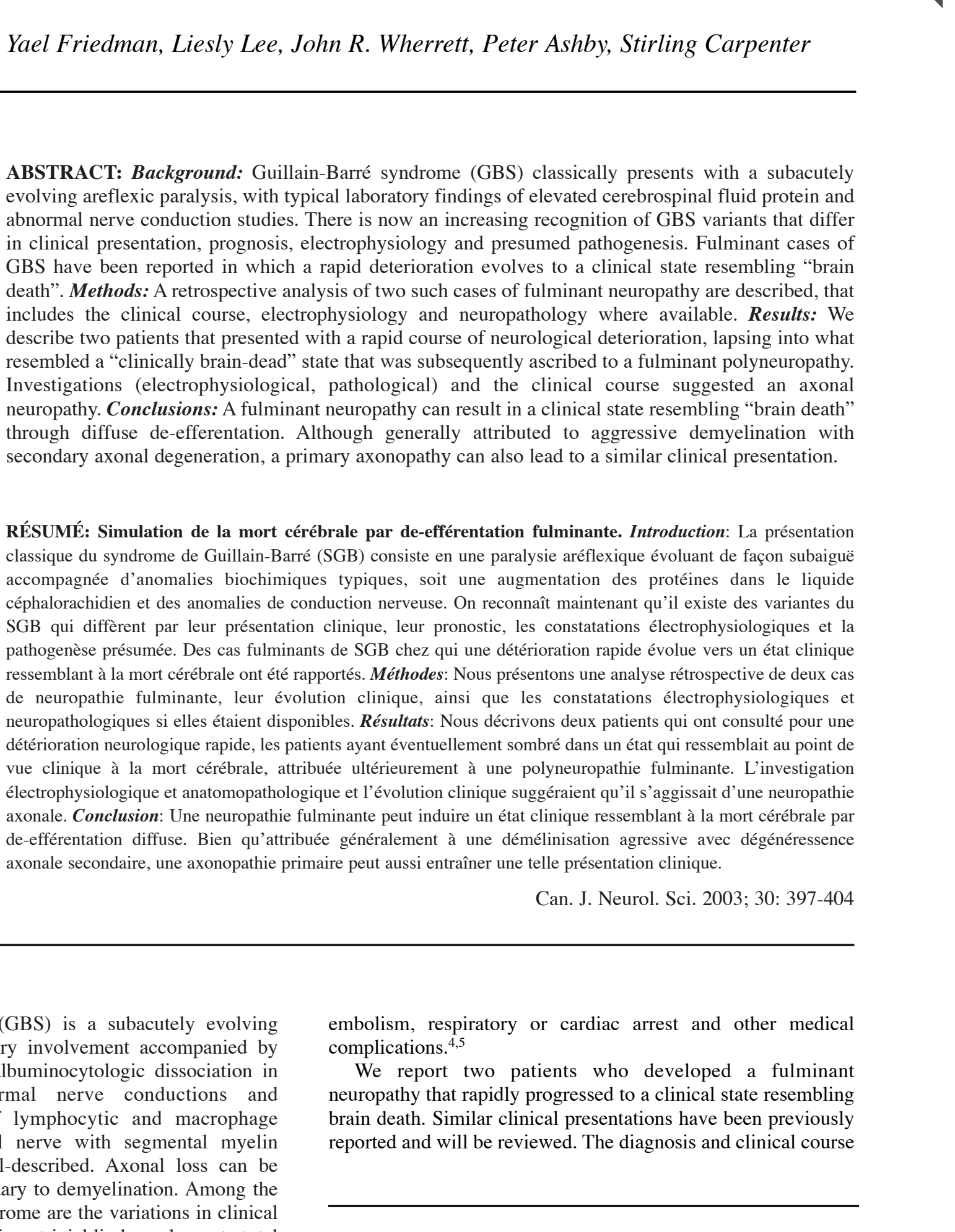

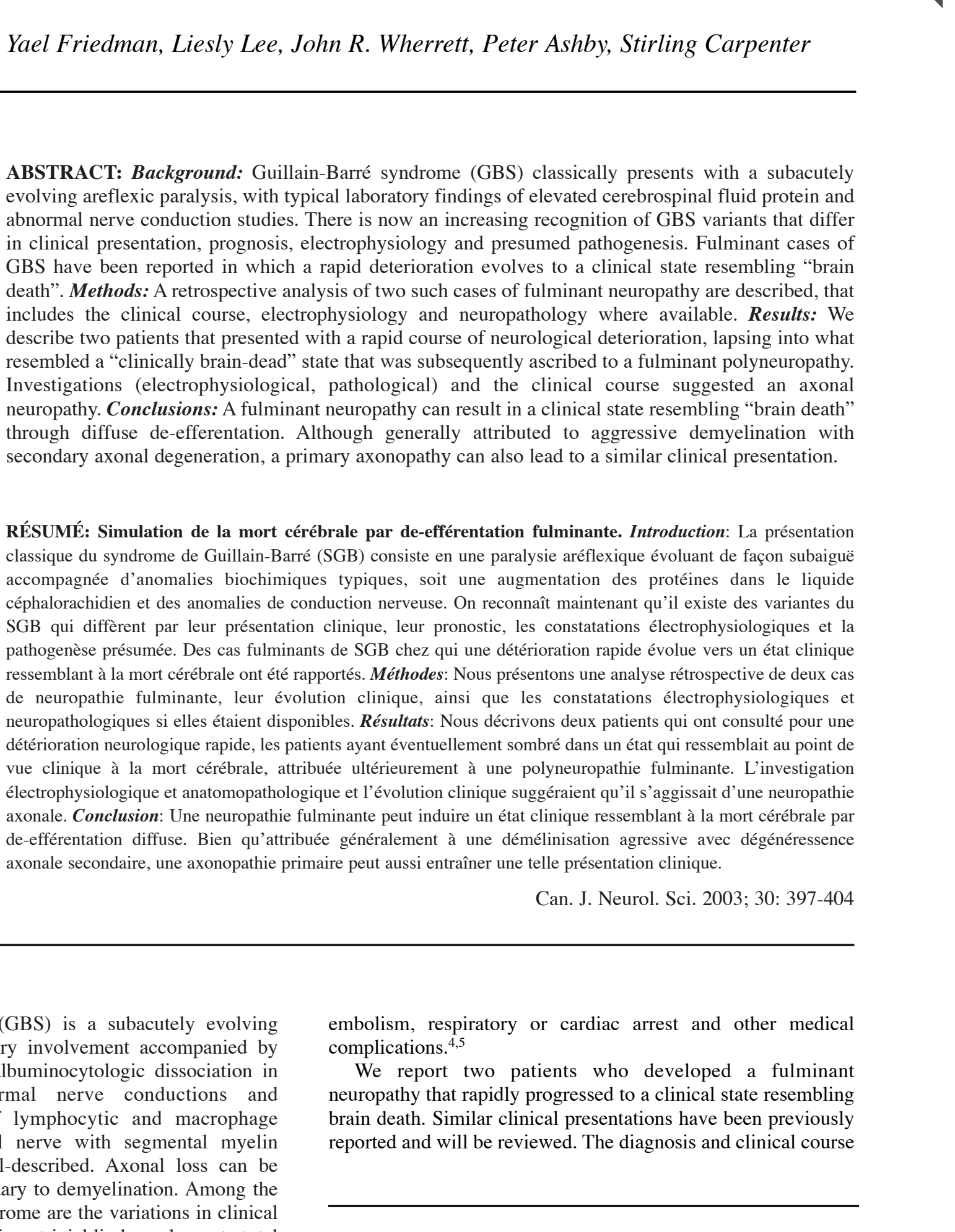

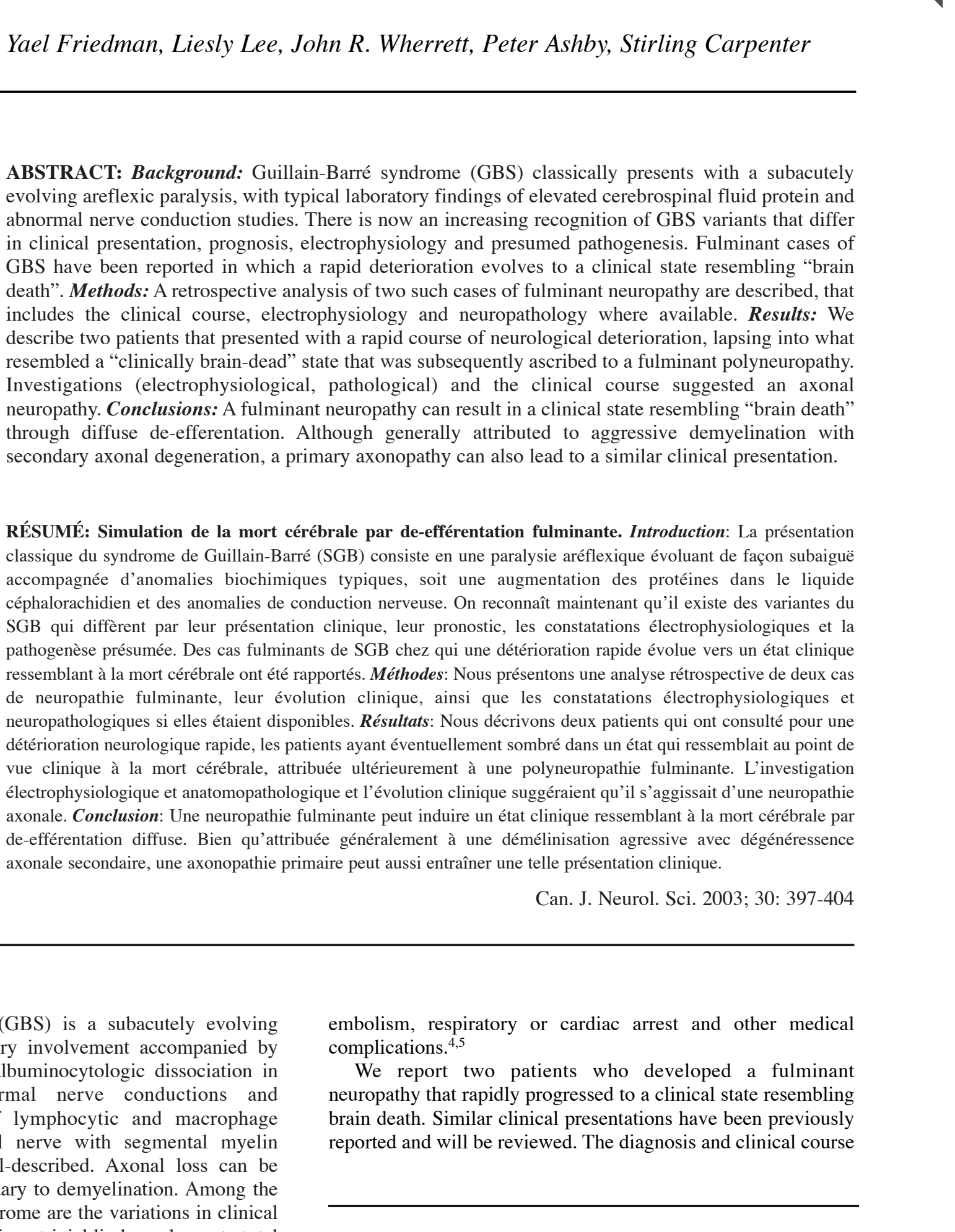

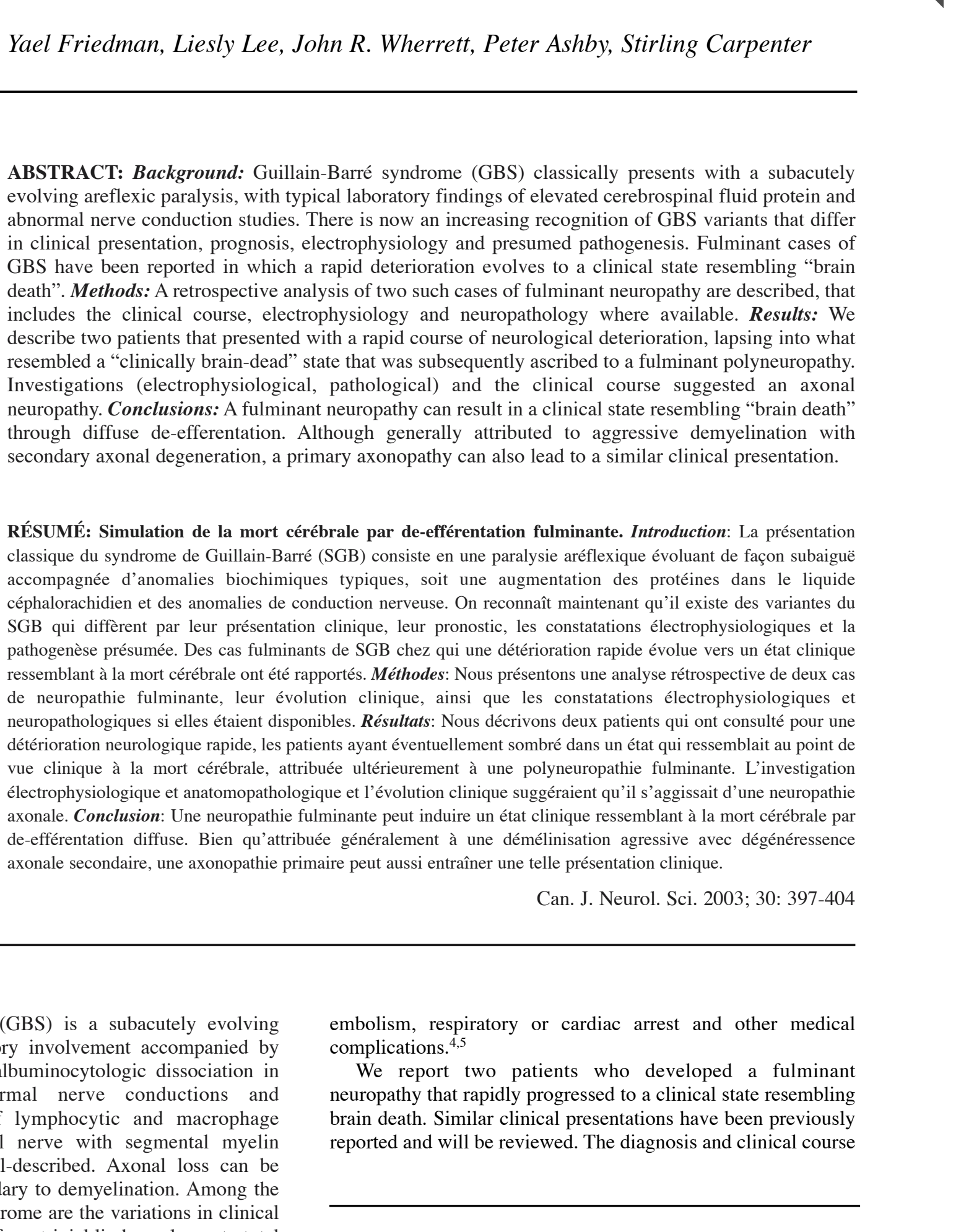

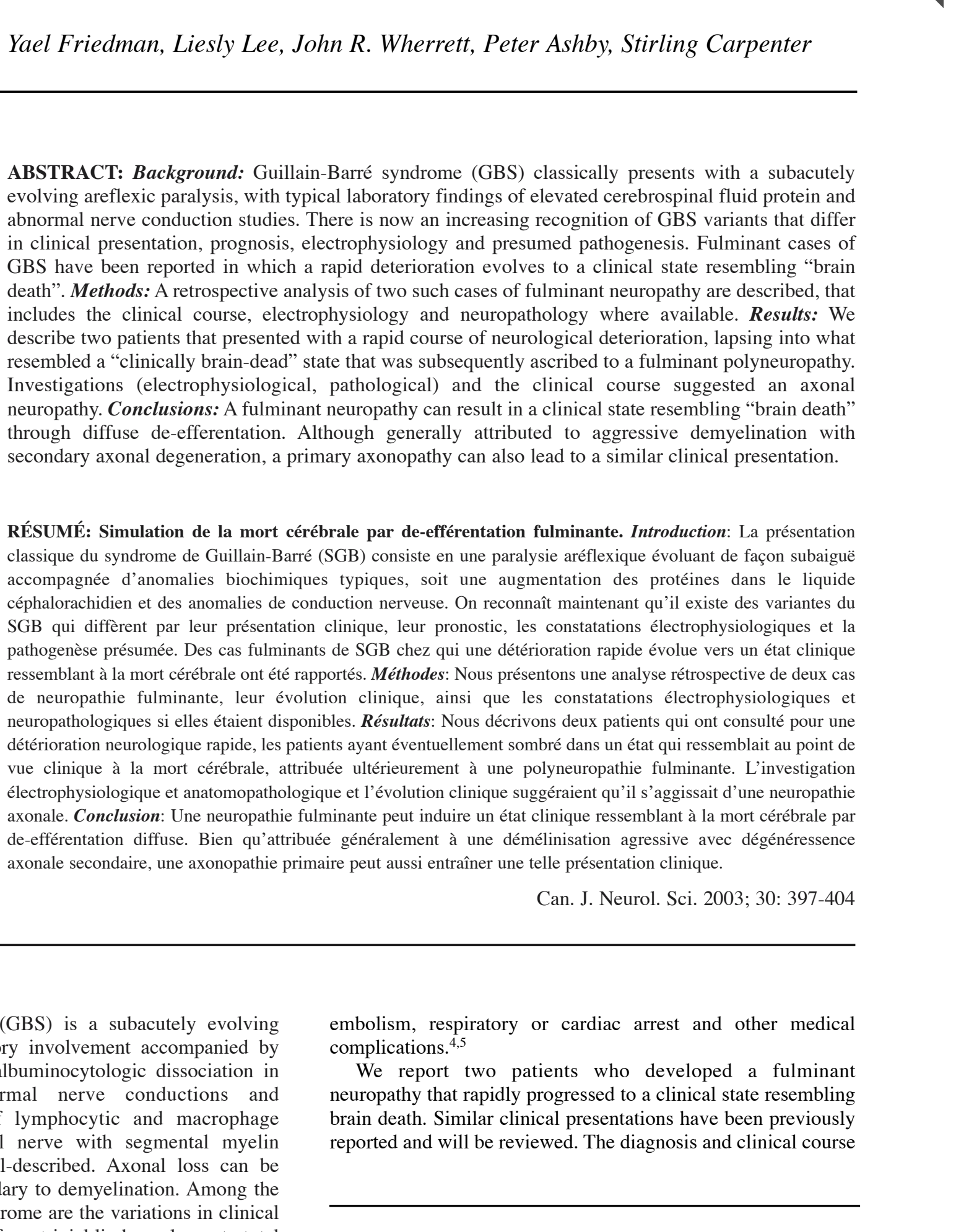

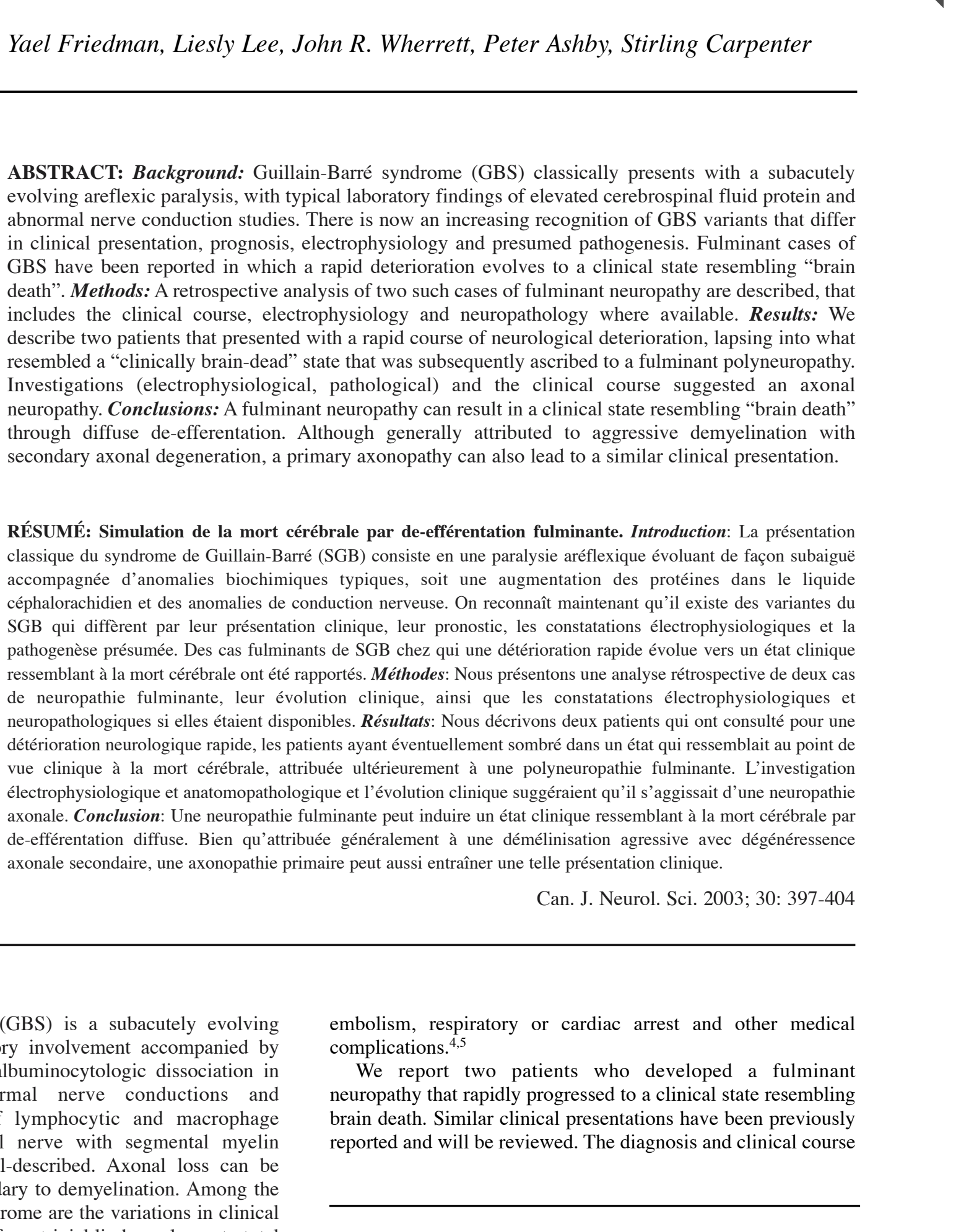

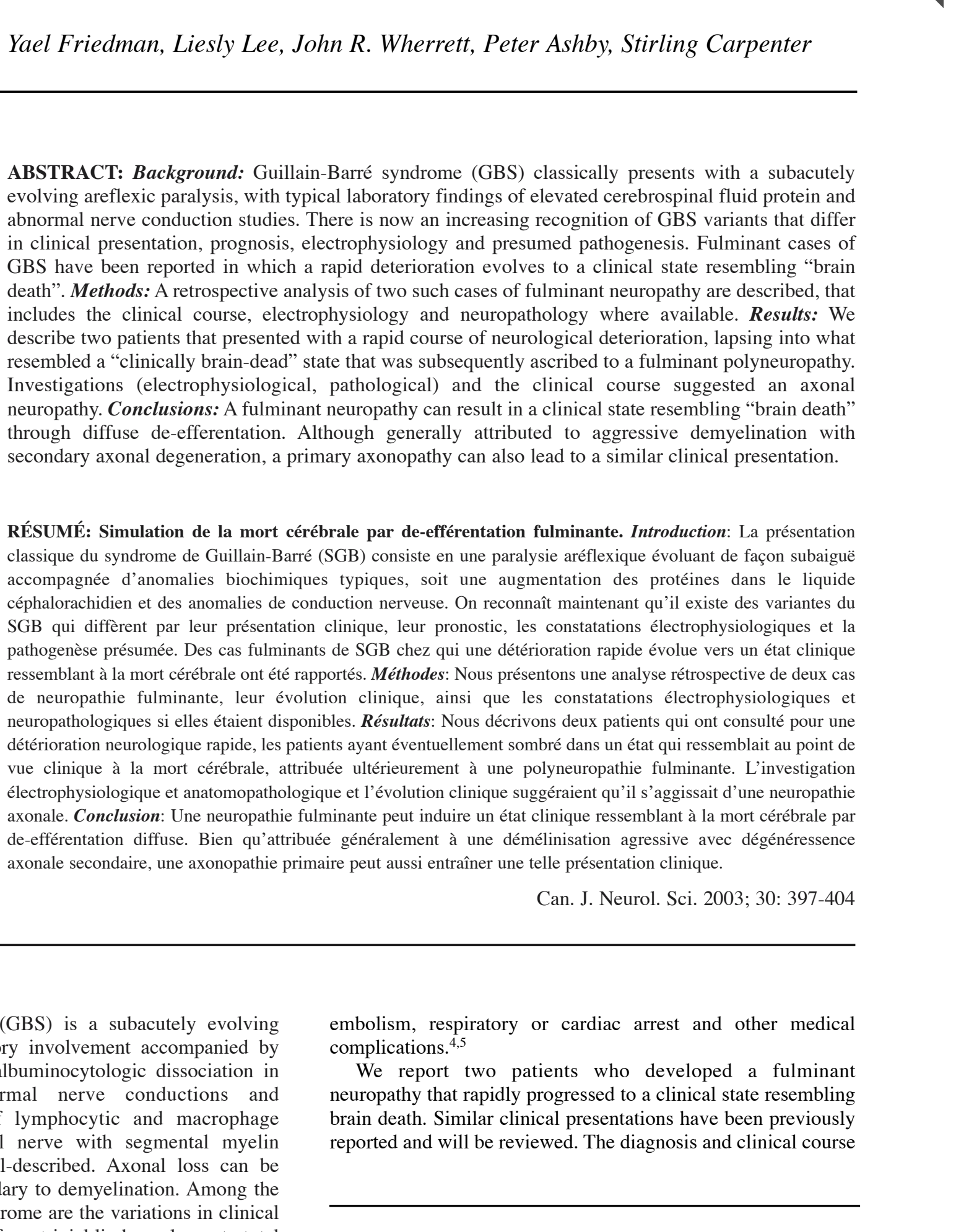
\begin{abstract}
axonale secondaire, une axonopathie primaire peut aussi entraîner une telle présentation clinique.
\end{abstract}

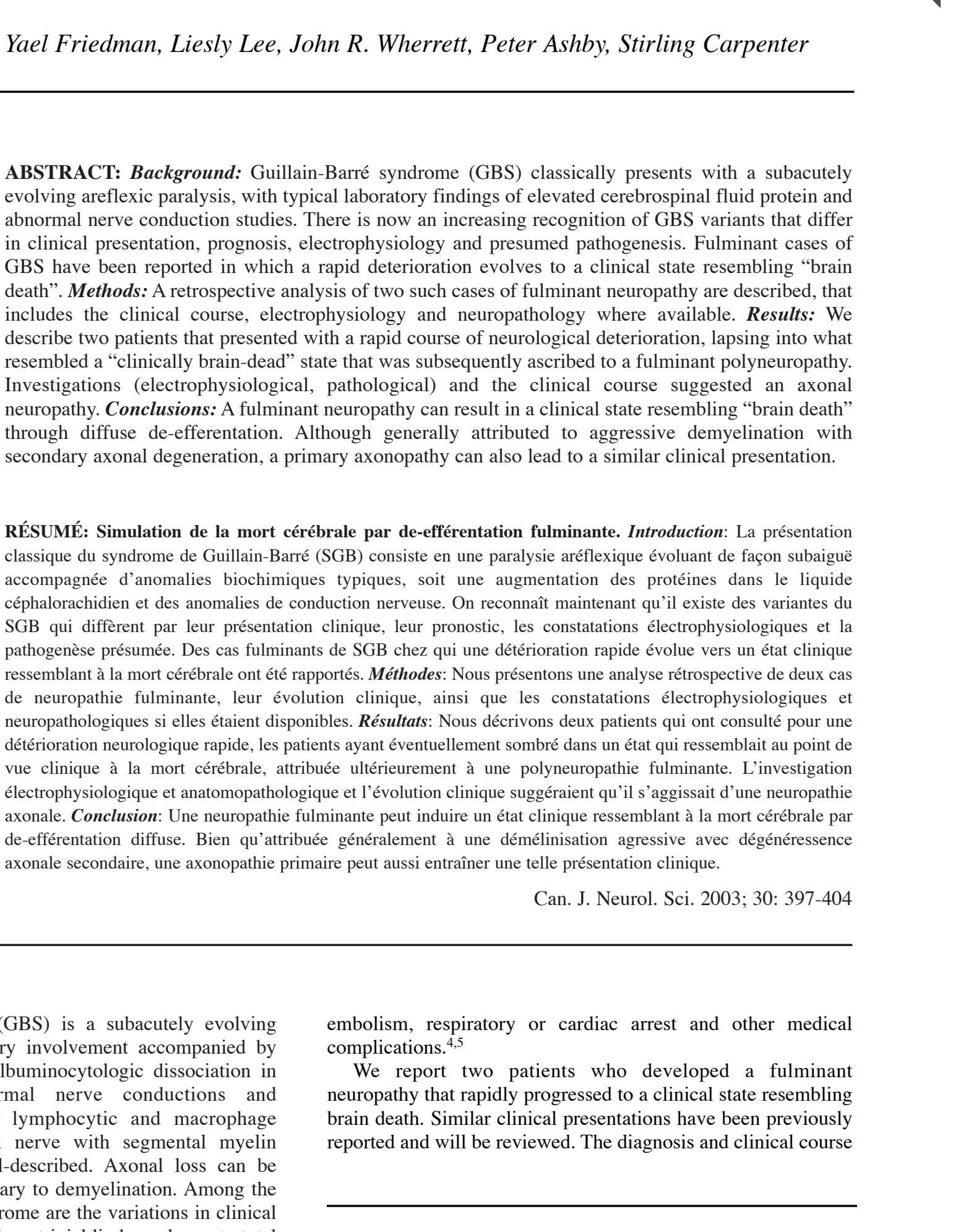

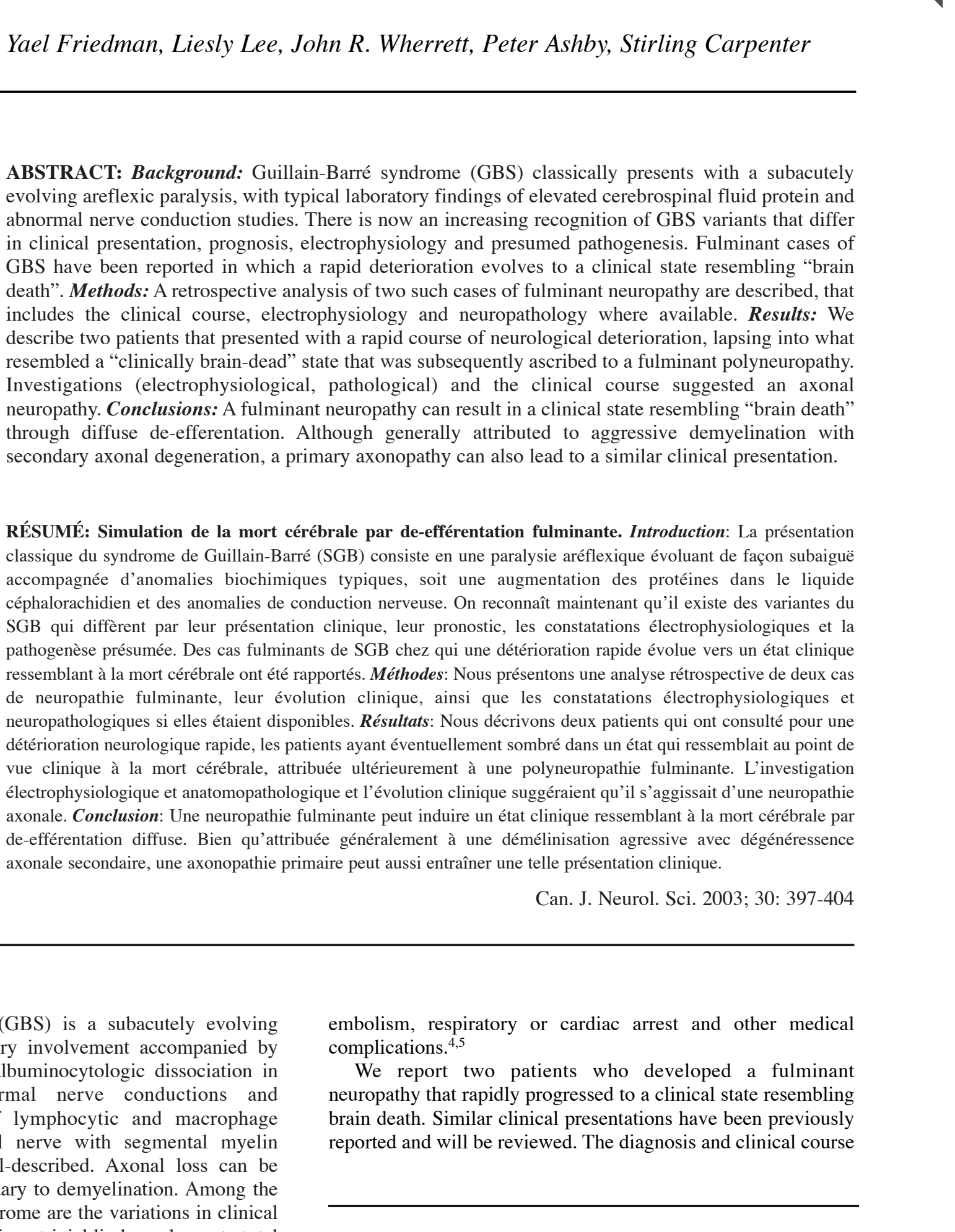

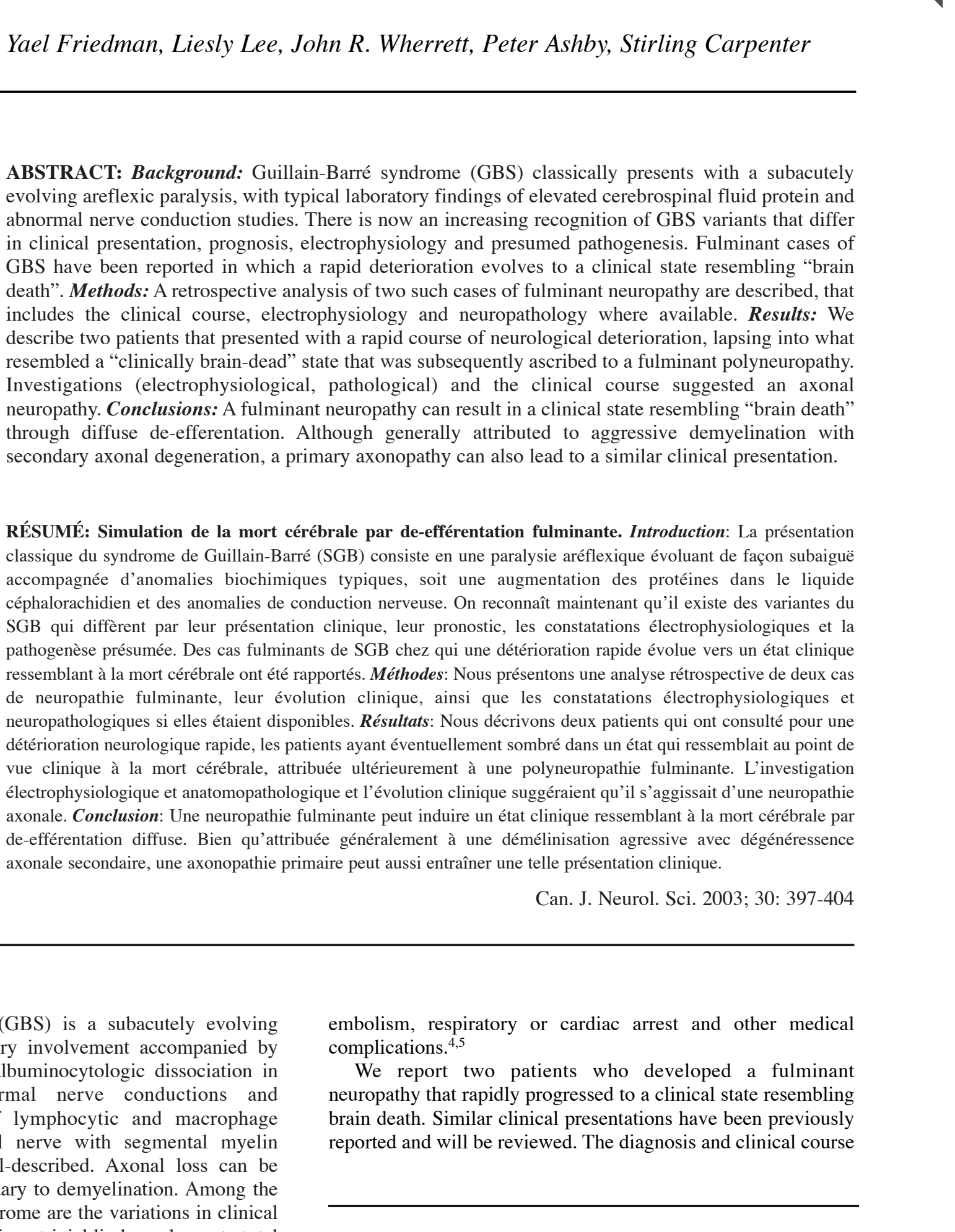

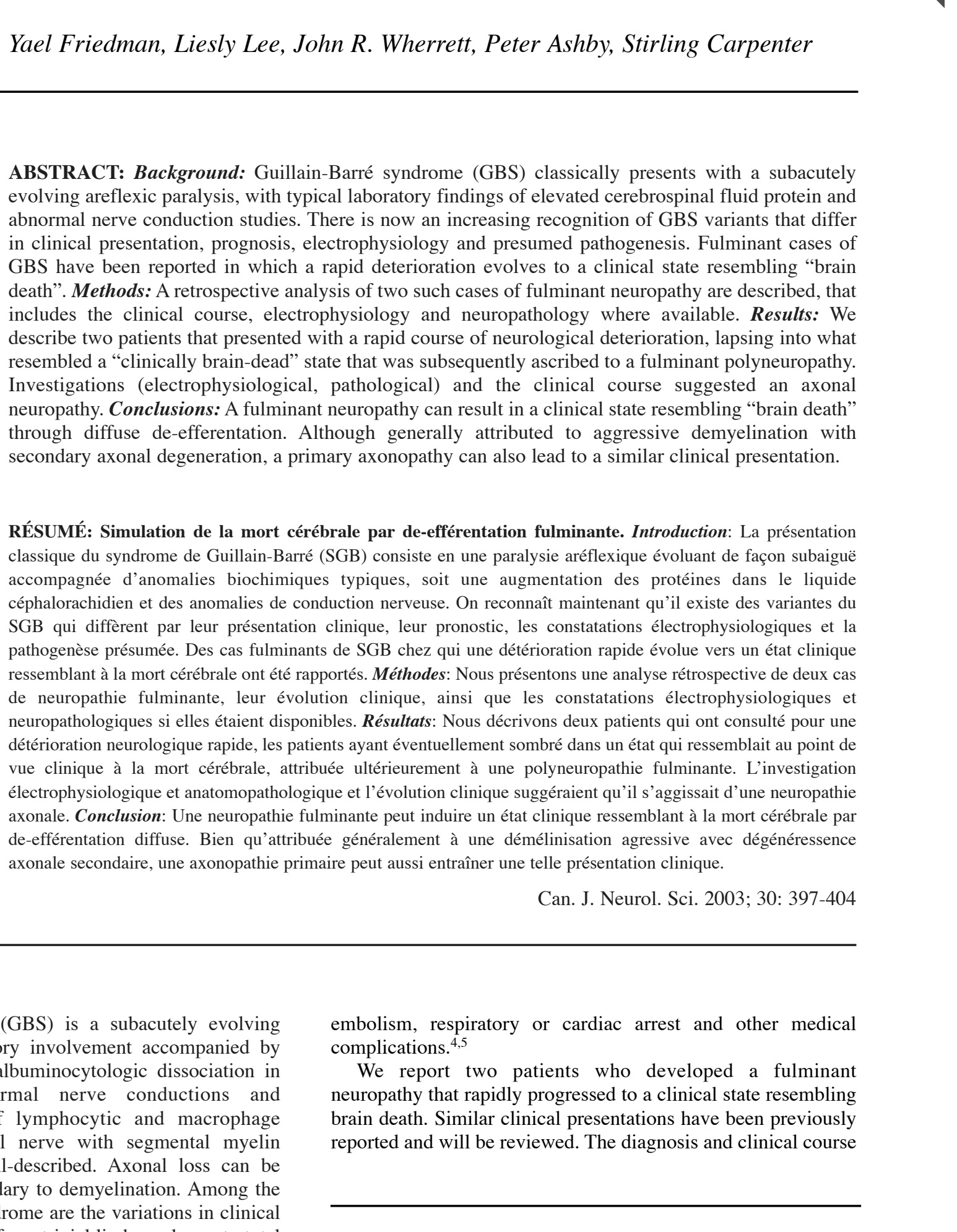

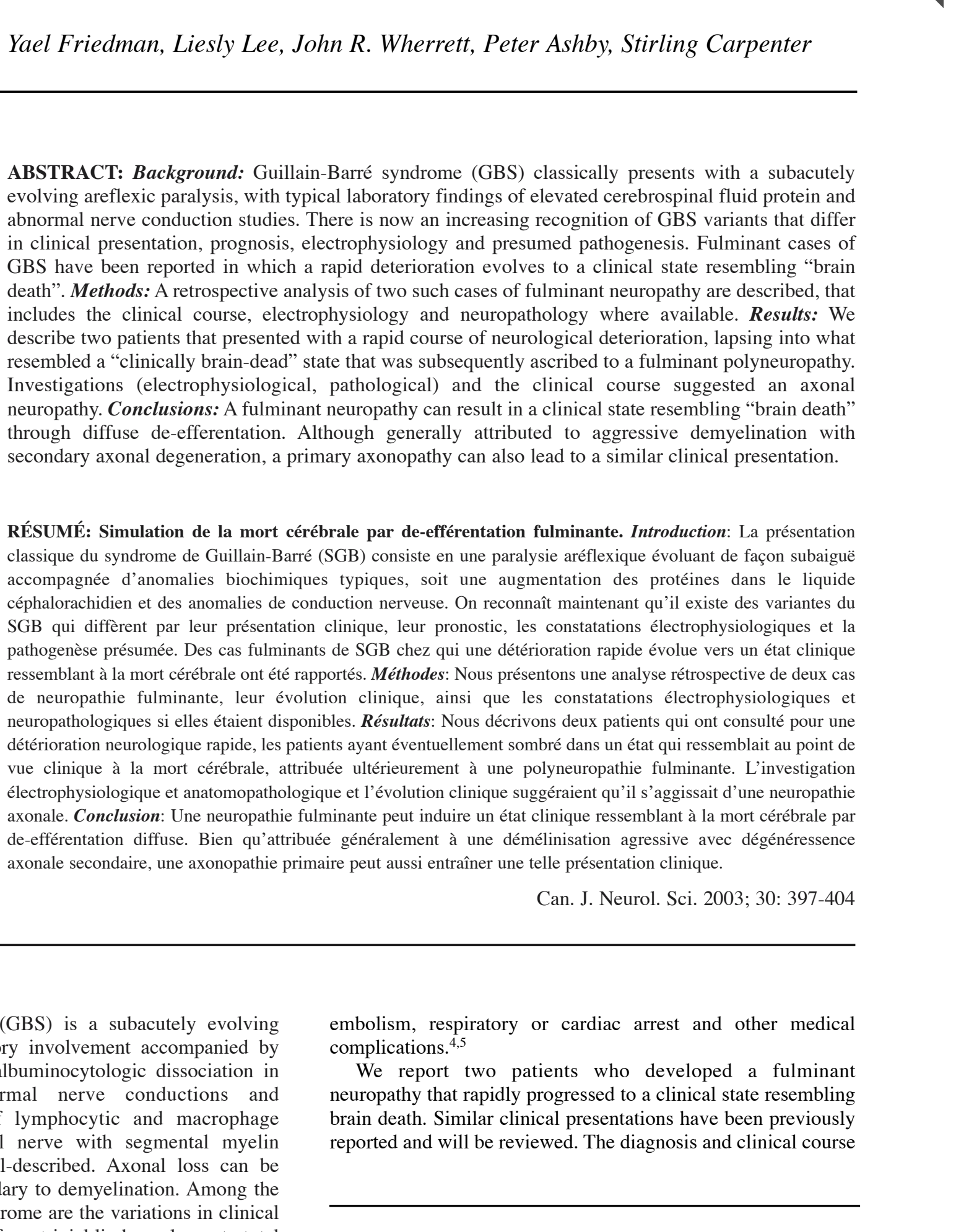

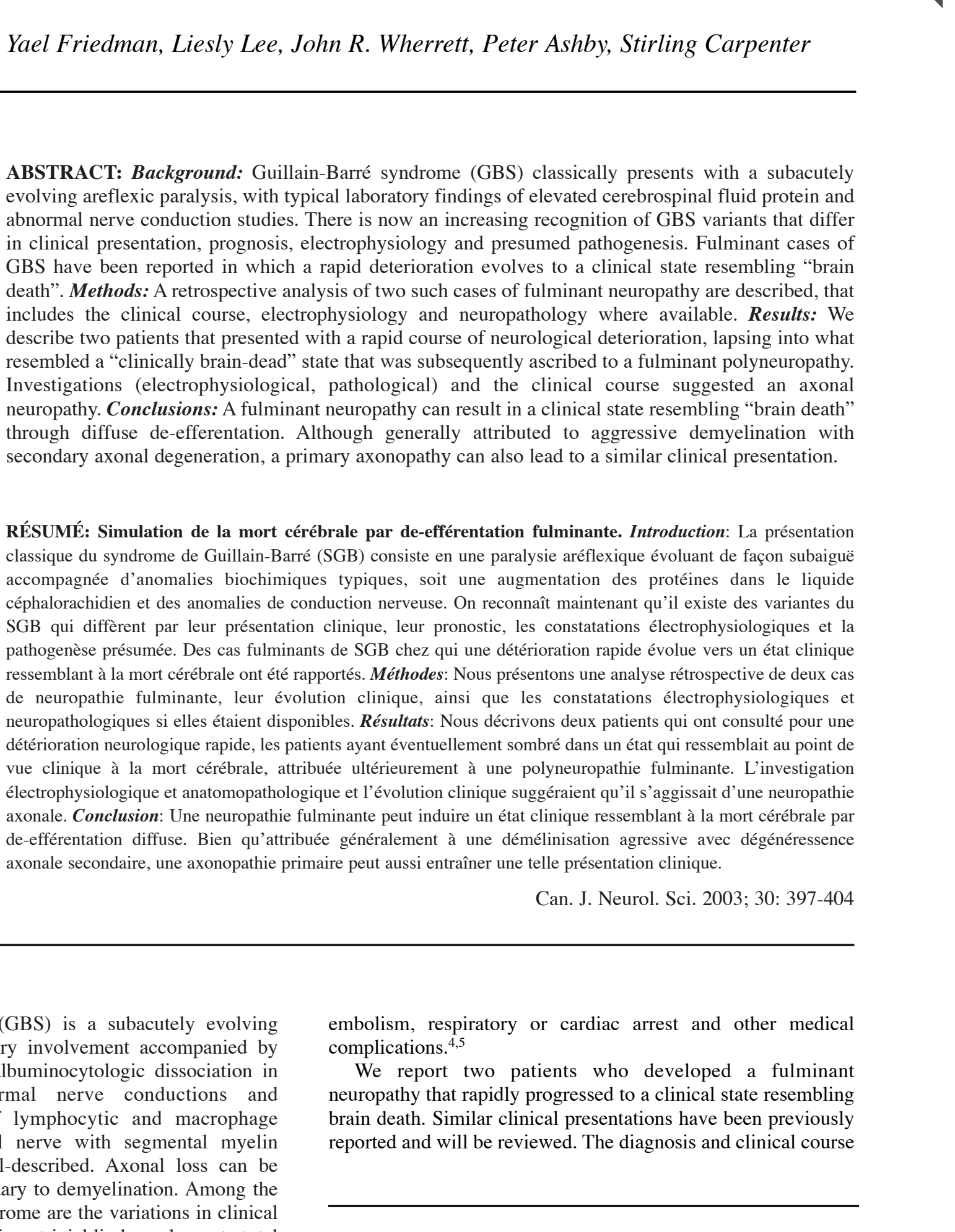

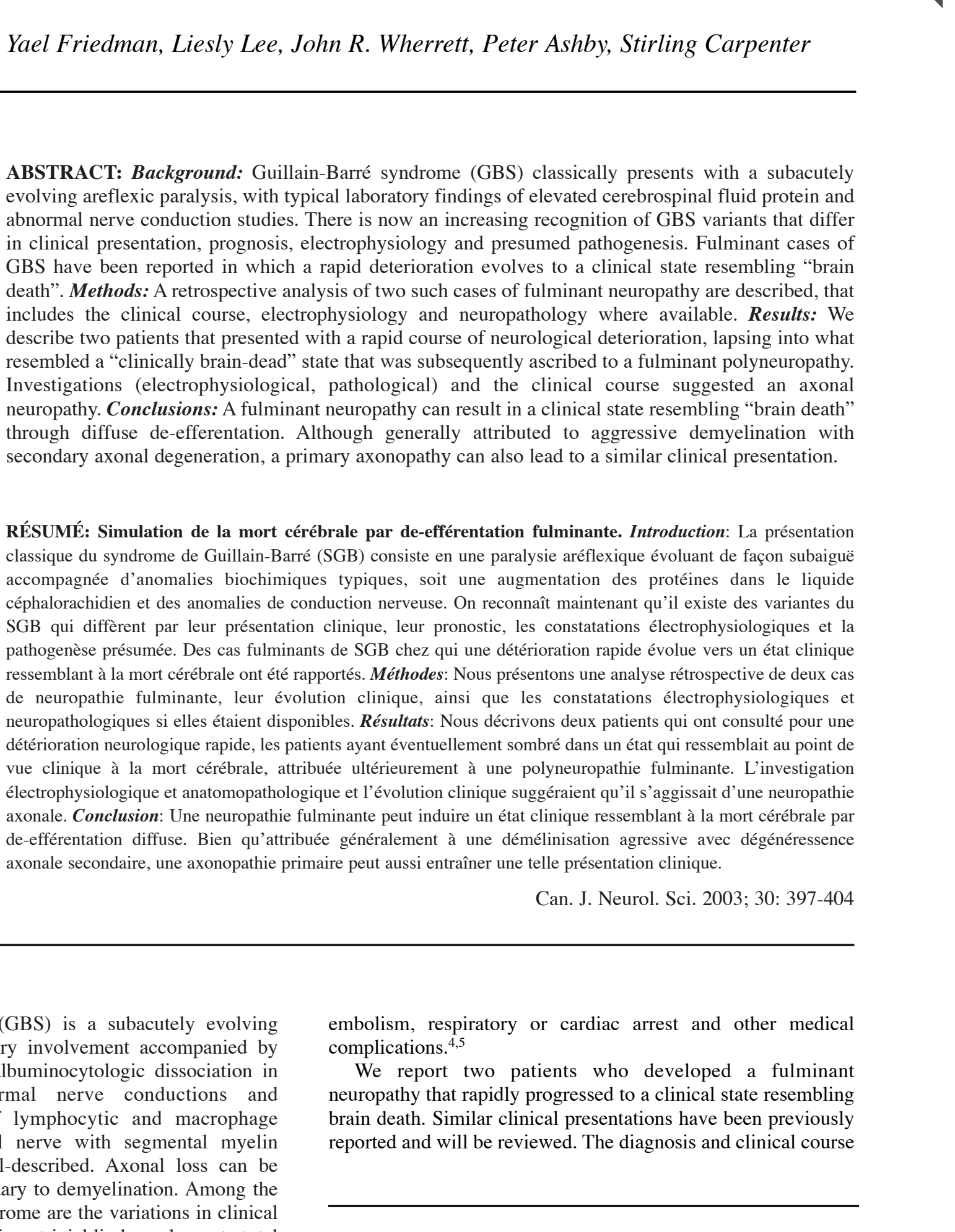

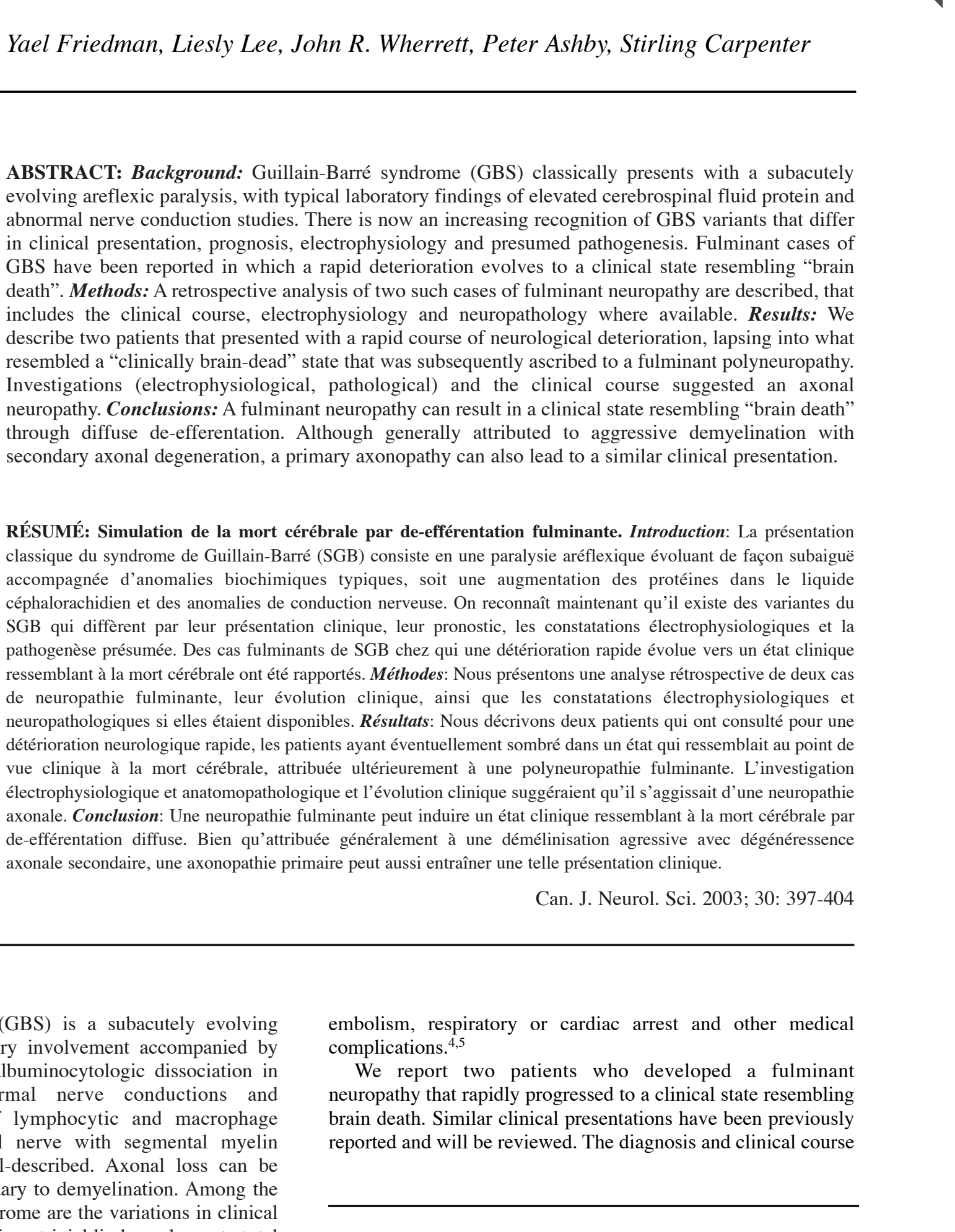

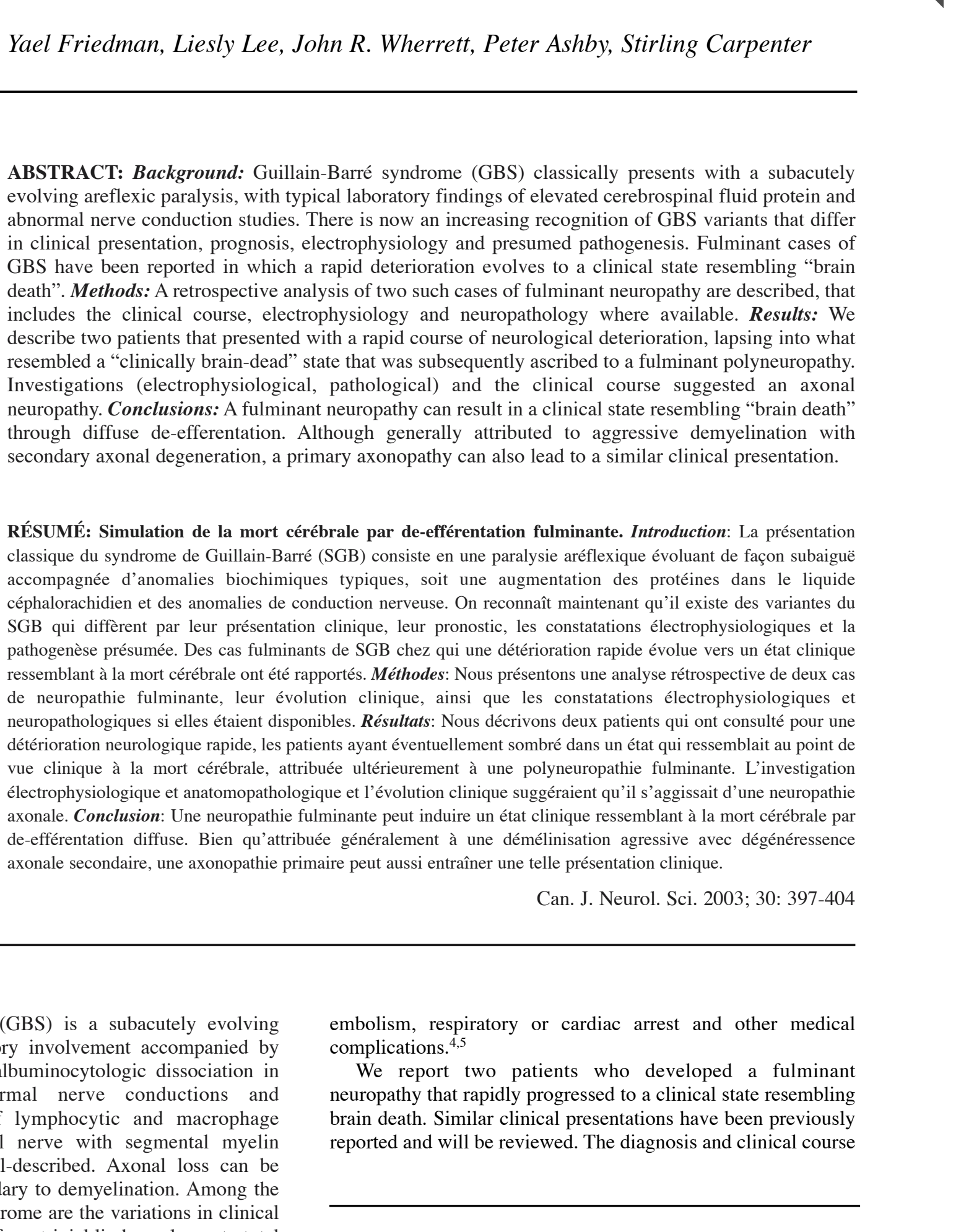

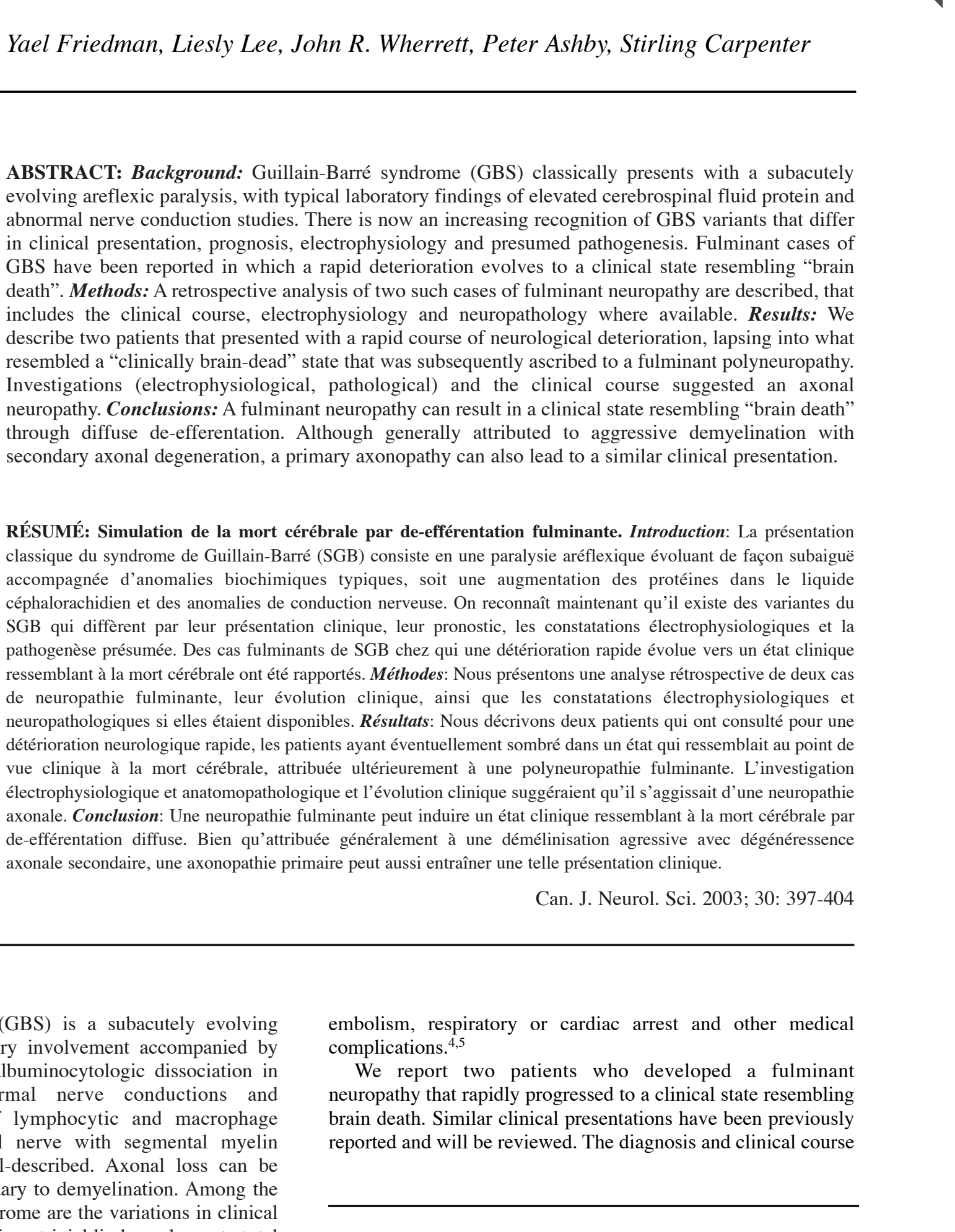

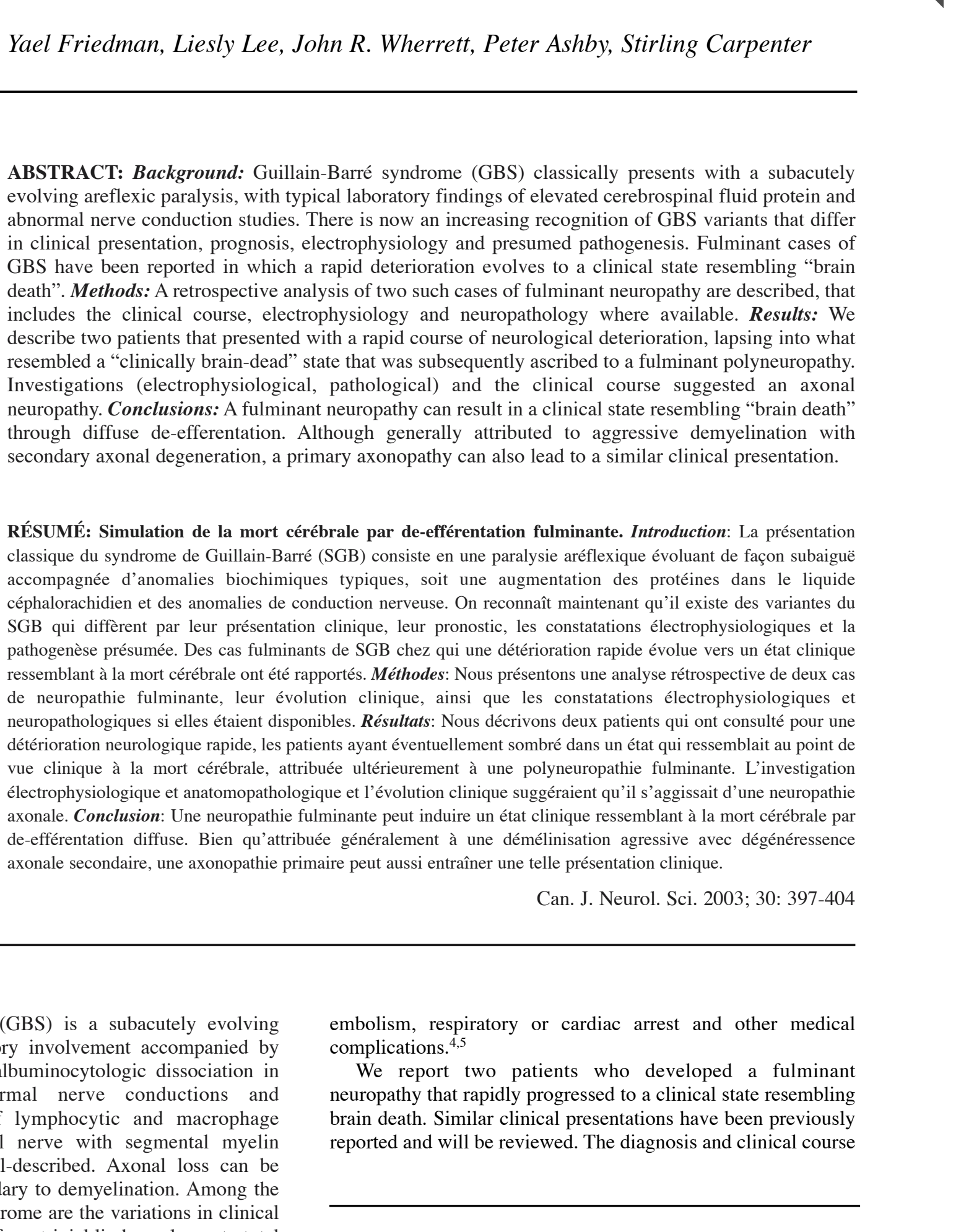

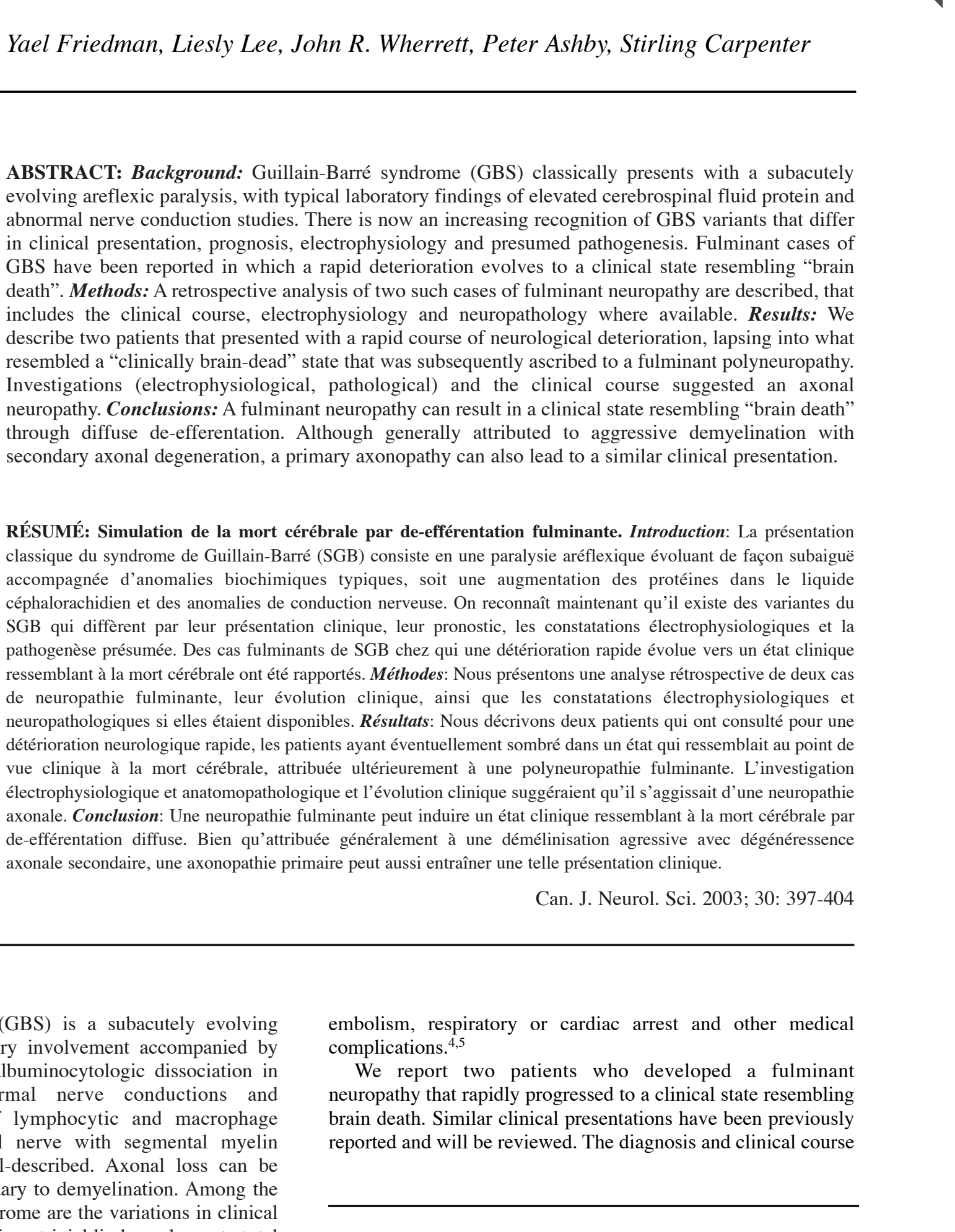

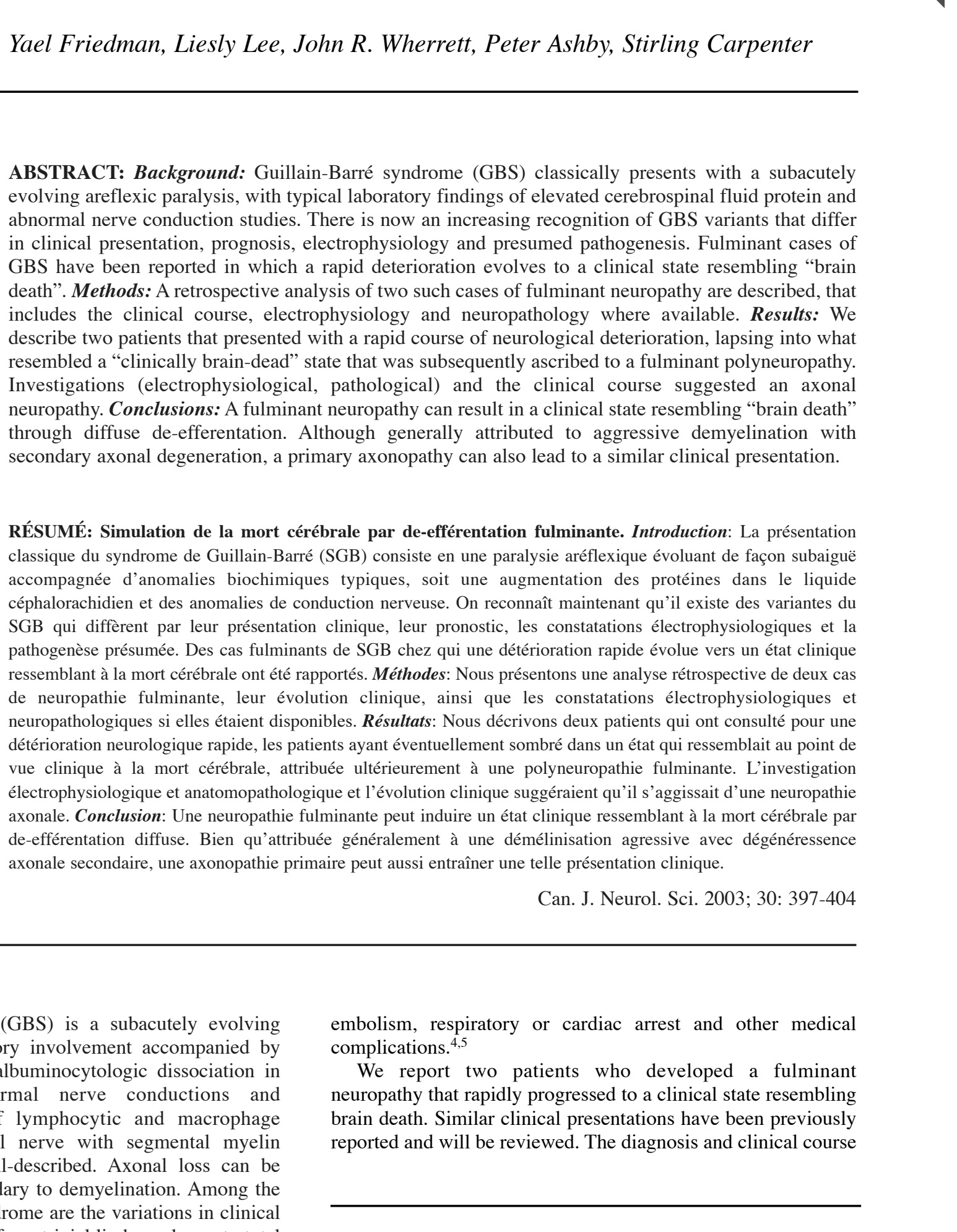

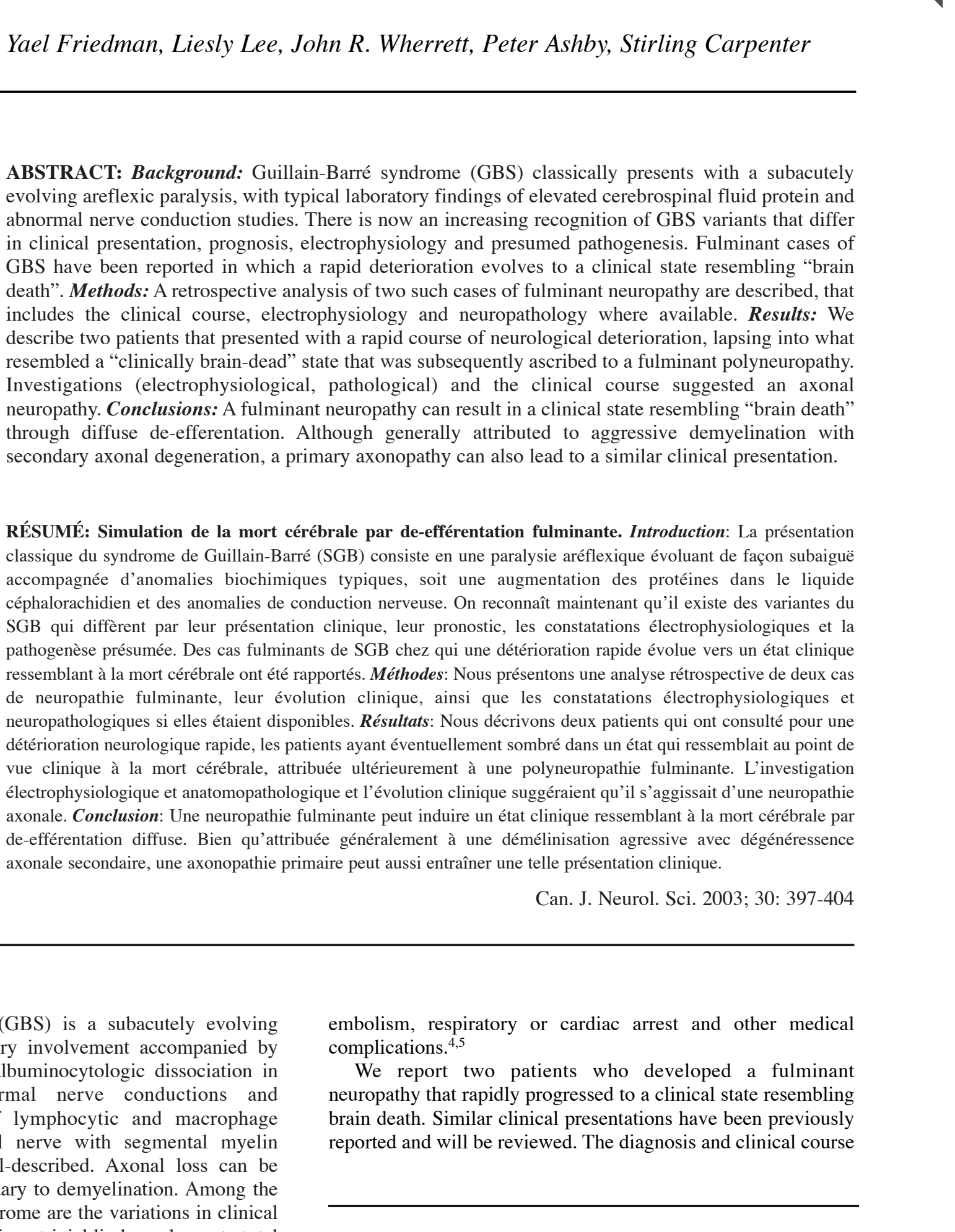

Guillain-Barré syndrome (GBS) is a subacutely evolving paralysis with variable sensory involvement accompanied by hyporeflexia, and typically, albuminocytologic dissociation in cerebrospinal fluid. Abnormal nerve conductions and pathological descriptions of lymphocytic and macrophage infiltration of the peripheral nerve with segmental myelin destruction $^{1-3}$ have been well-described. Axonal loss can be present, and is usually secondary to demyelination. Among the intriguing aspects of this syndrome are the variations in clinical course, with severity ranging from trivial limb weakness to total paralysis requiring ventilatory assistance. The majority of patients (75-80\%) recover fully (or almost so), but a small percentage $(3-8 \%)$ still die secondary to sepsis, pulmonary

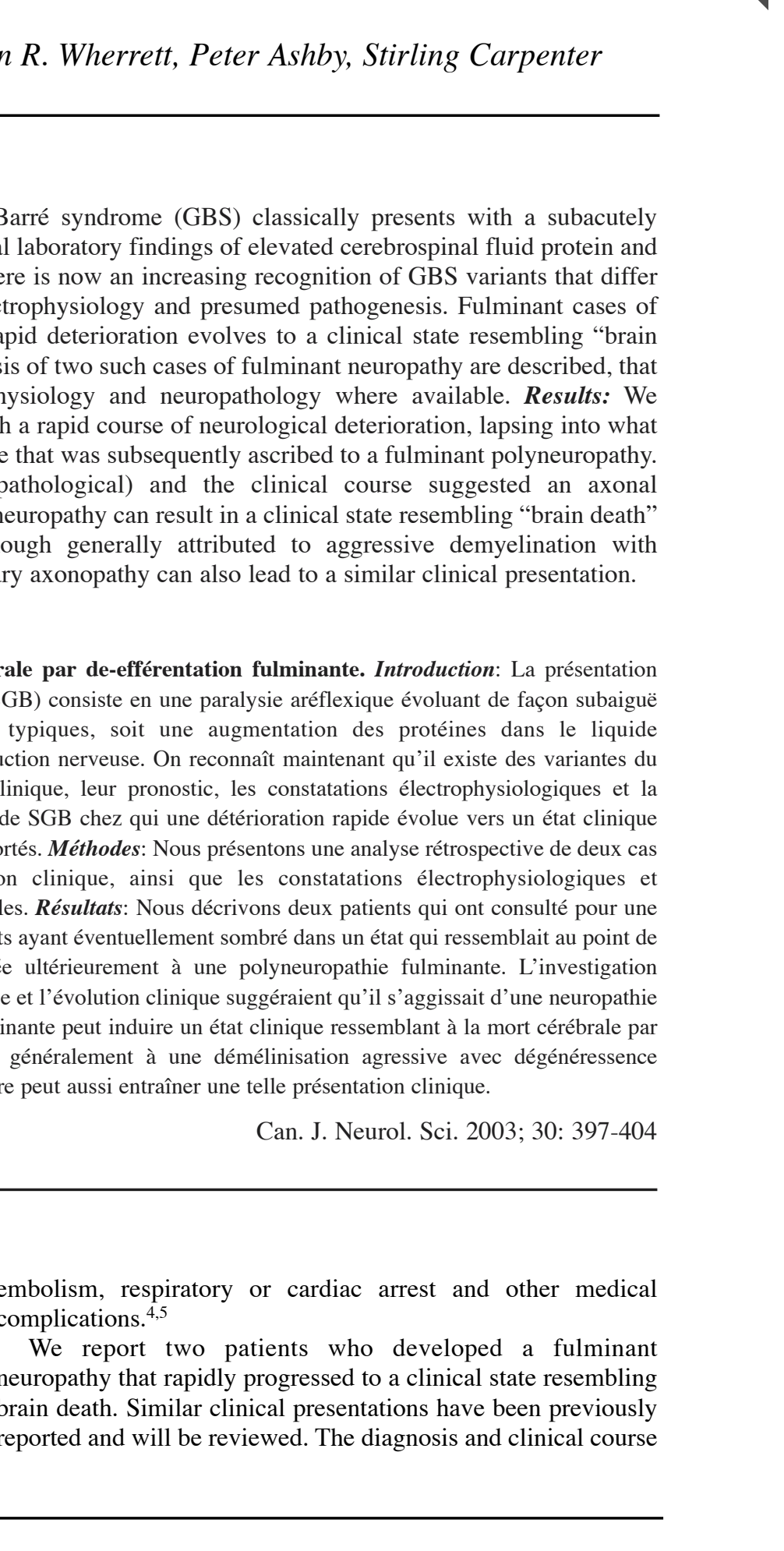

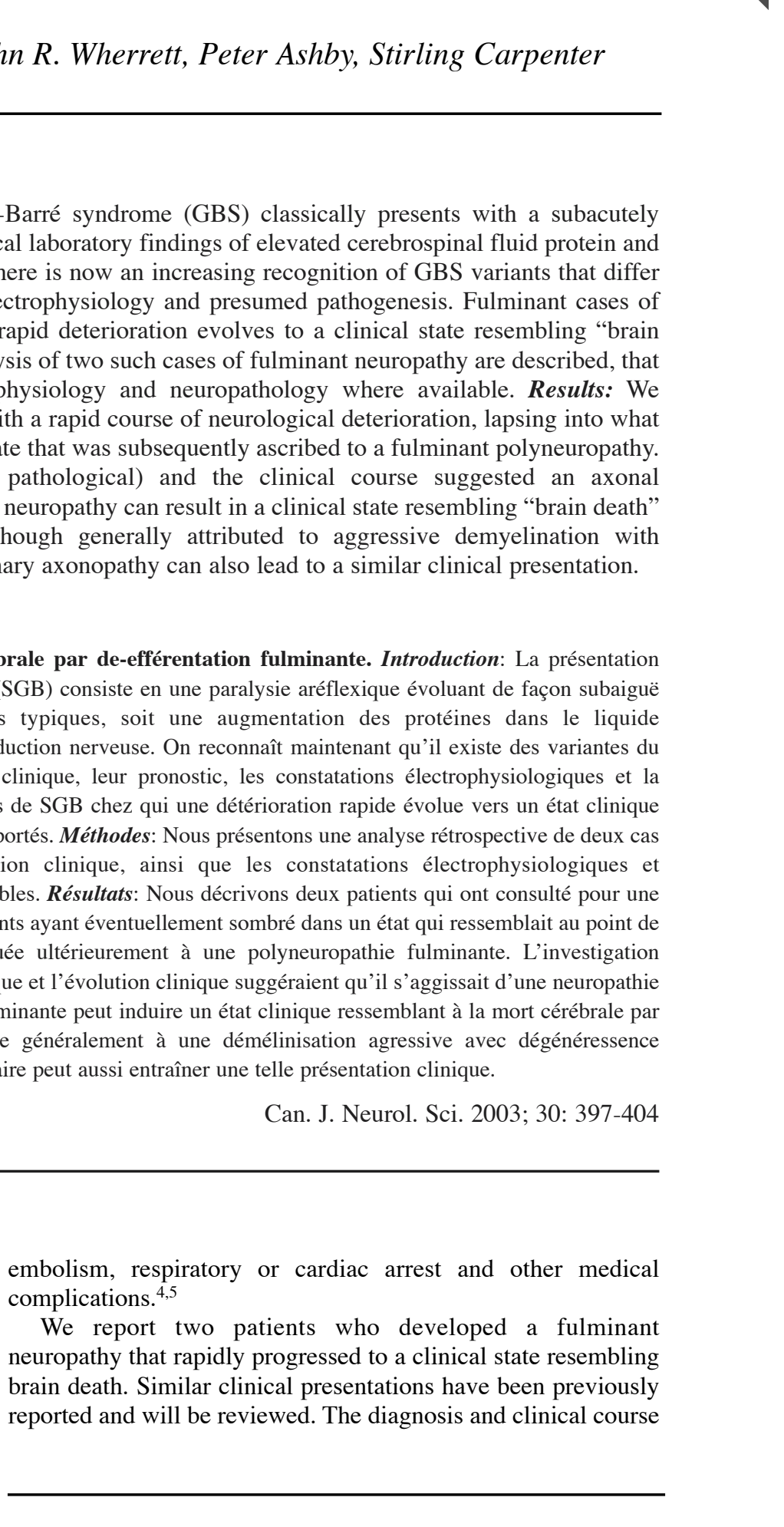

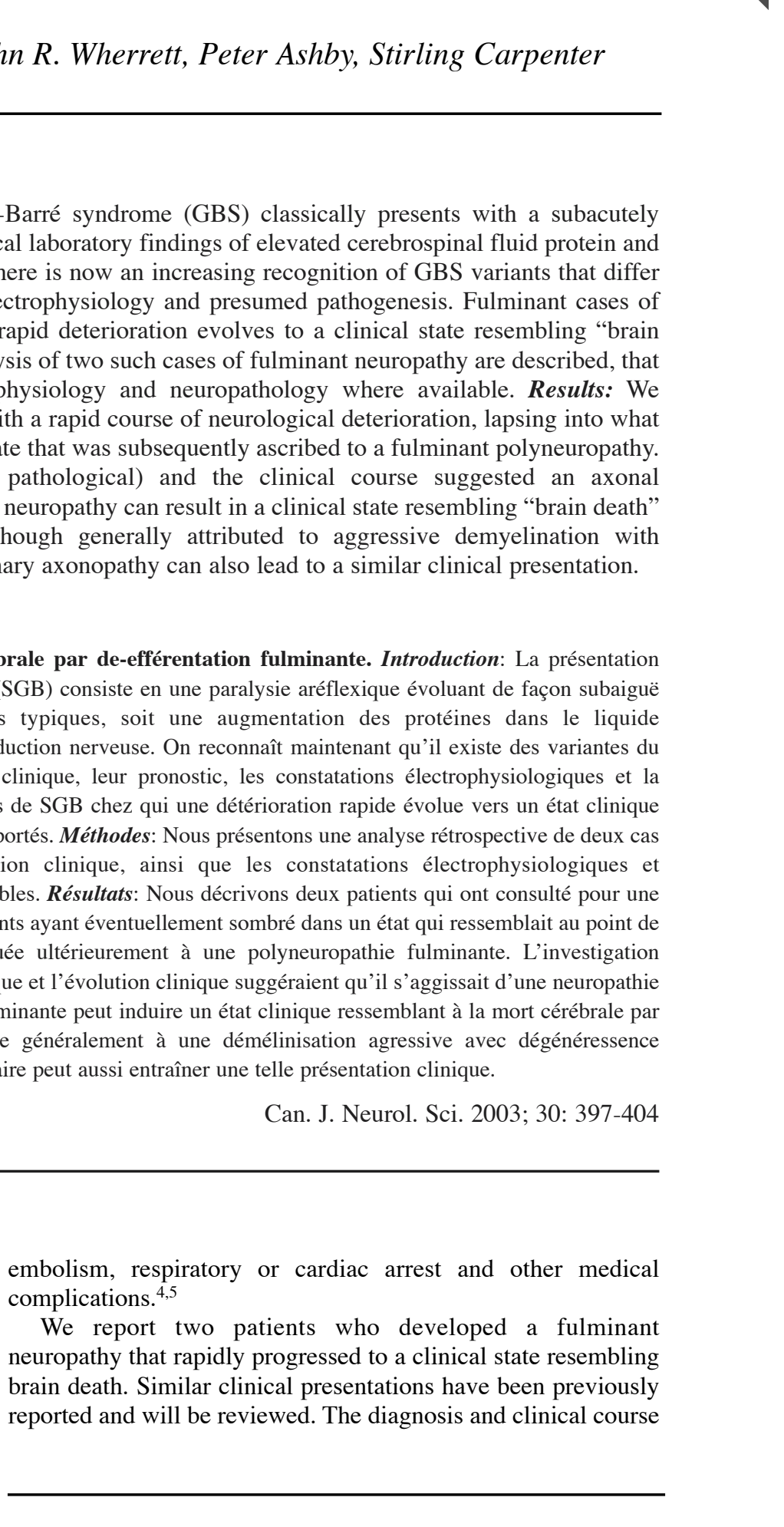

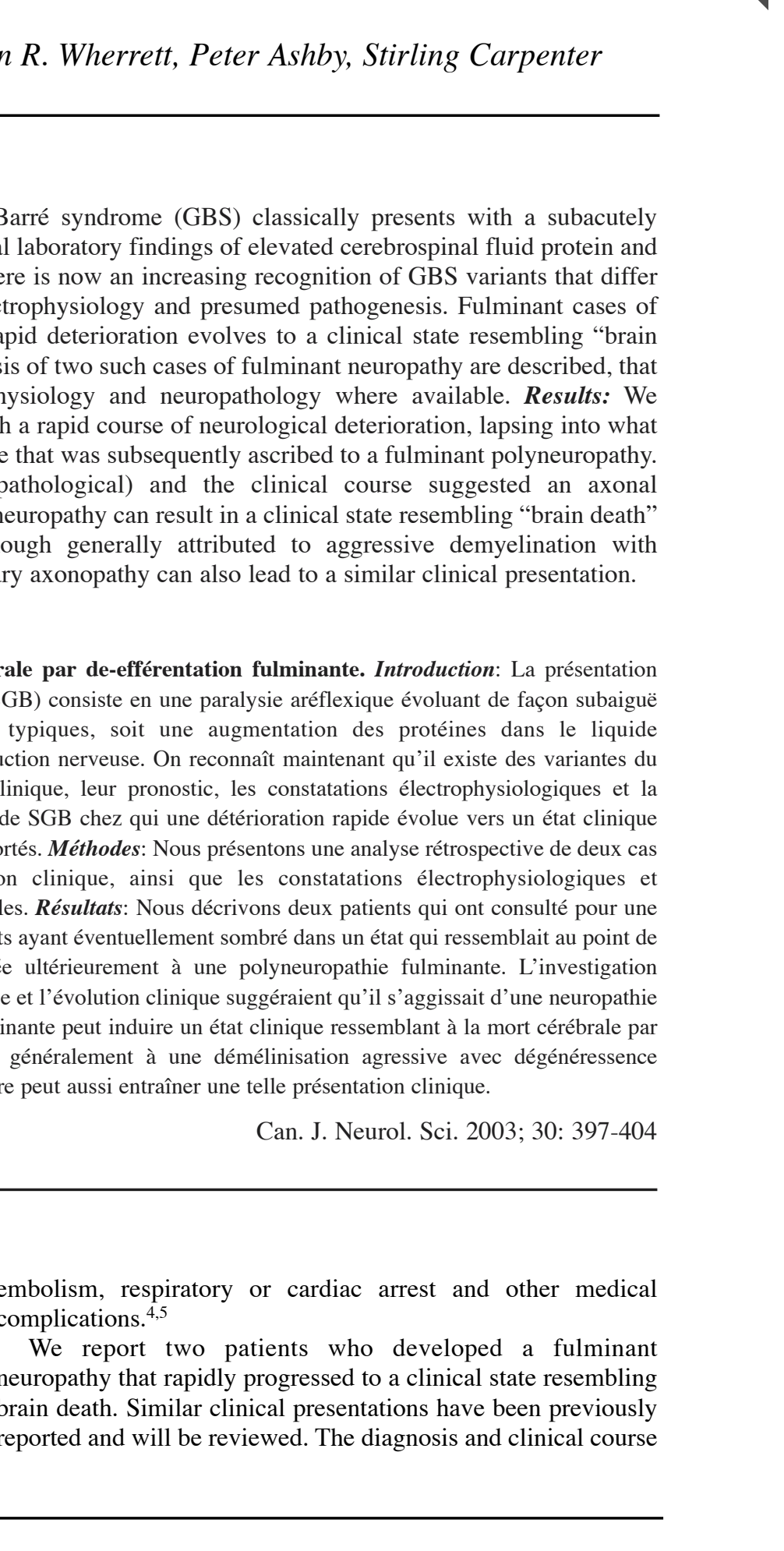

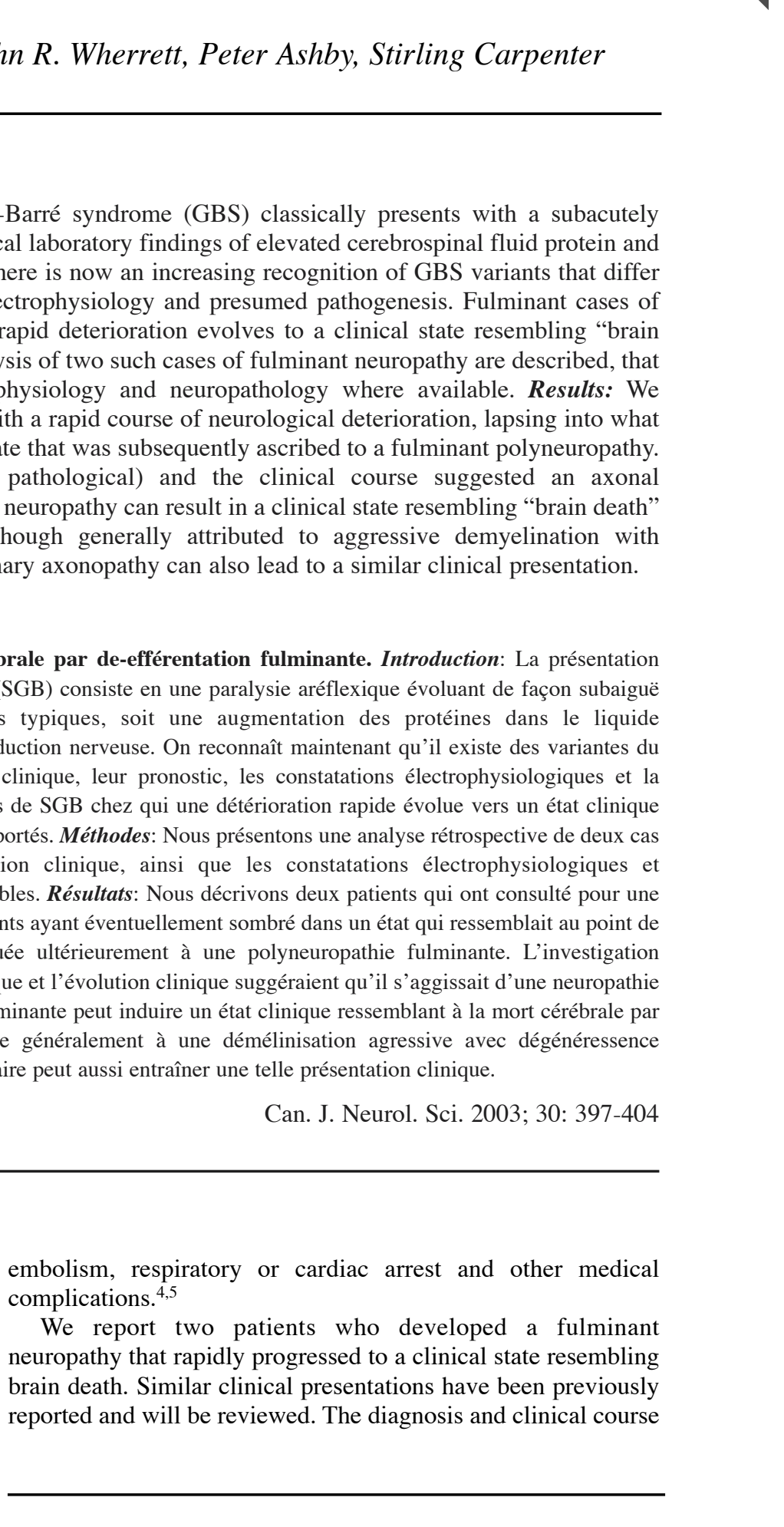

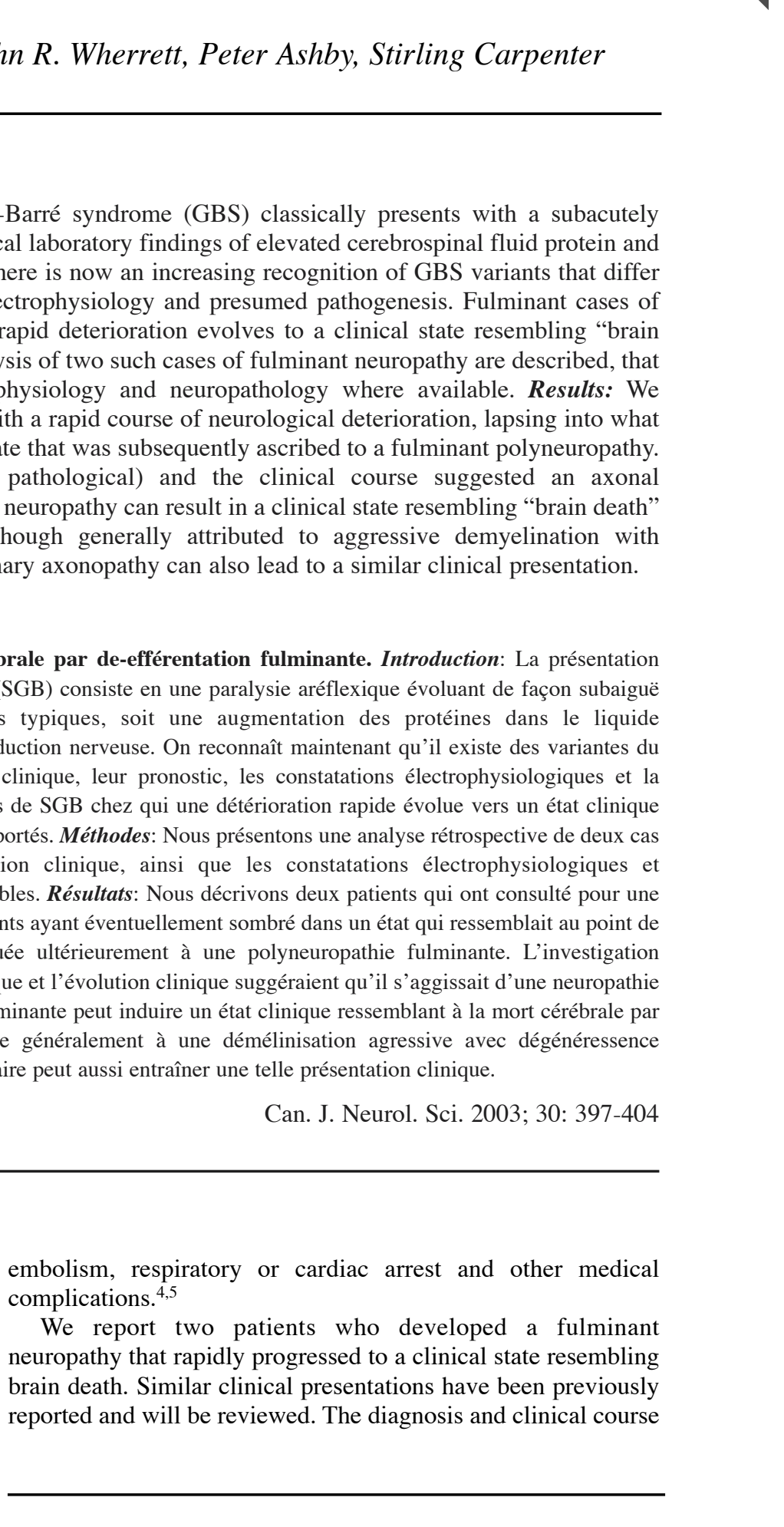

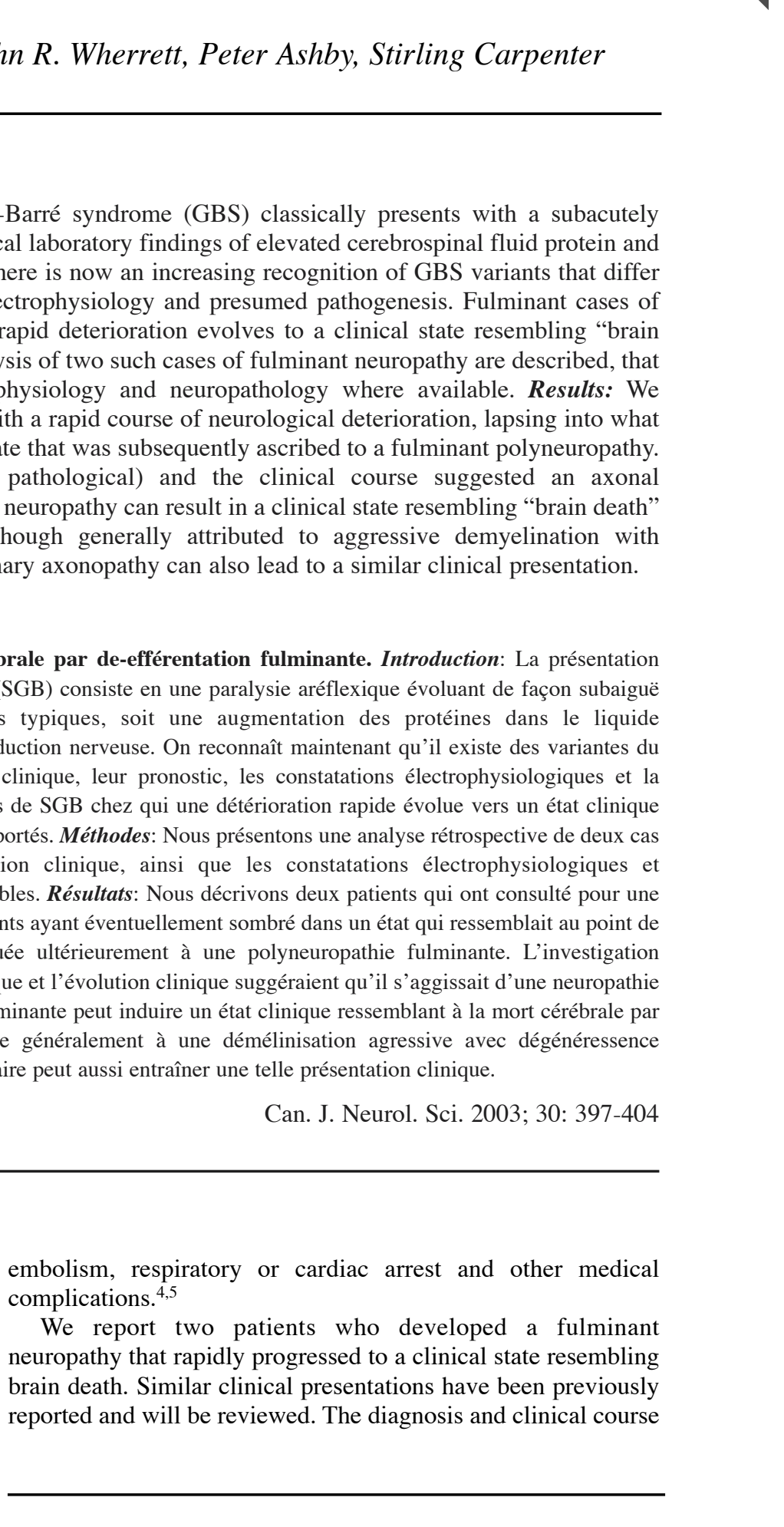

From the Division of Neurology, University of Toronto, Toronto, Ontario Canada. ReCEIVED JANUARY 22, 2003. ACCEPTED IN FINAL FORM JunE 9, 2003. Reprint requests to: Liesly Lee, Department of Medicine (Neurology), Sunnybrook and Women's College Health Sciences Centre, A-411, 2075 Bayview Avenue, Toronto, Ontario M4N 3M5 Canada. 
of our two cases is discussed in light of recent advances in the understanding of GBS.

\section{Case Reports}

\section{Patient 1}

A 57-year-old woman developed slurred speech and numbness of both lower extremities five days following flu-like symptoms that included a sore throat and headache. On day 3 following neurological symptom onset, she was febrile and became stuporous. There was no meningismus. Pupillary reactions were sluggish and the gag reflex was absent. There was only limb withdrawal to noxious stimuli. Tendon reflexes were absent, but plantar responses were bilaterally extensor. A CT scan of the head was normal. Laboratory investigations revealed a leukocytosis with $24.1 \times 10^{9}$ cells/L. Drug screen was negative. A lumbar puncture revealed 50 leukocytes with a polymorphonuclear predominance (64\%). A provisional diagnosis of brainstem encephalitis was made and treatment with acyclovir, ampicillin and ceftriaxone was initiated. Magnetic resonance imaging (MRI) of the brain on day 4 of symptom onset was normal. Forty-eight hours later (day 6 of symptom onset), she lost all brainstem reflexes. The patient did not breathe spontaneously, did not have any stretch reflexes and no longer withdrew to noxious stimuli. She appeared to meet the criterion of brain death. However, on day 8, the cerebral perfusion study was normal, contradicting the clinical impression. Electroencephalography revealed diffuse theta activity. An MRI with gadolinium was repeated three days later (with high-resolution cuts through the brainstem), which was again normal. On day 13, a repeat cerebrospinal fluid (CSF) examination revealed 80 white cells (99\% lymphocytes) and cultures were once again negative for mycobacterial, bacterial, viral and fungal growth.

Table 1: Electromyography (EMG) and nerve conduction results in our two reported cases

\section{PATIENT 1}

Study 1 (7 weeks post presentation)

\begin{tabular}{|c|c|c|c|c|c|c|c|c|}
\hline \multirow{2}{*}{$\begin{array}{l}\text { Nerve } \\
\text { Right Median } \\
\text { Right Ulnar }\end{array}$} & \multicolumn{3}{|c|}{ MOTOR } & \multicolumn{3}{|c|}{ SENSORY } & \multicolumn{2}{|l|}{ EMG } \\
\hline & \multirow{3}{*}{\multicolumn{3}{|c|}{$\begin{array}{l}\mathrm{NR} \\
\mathrm{NR}\end{array}$}} & \multirow{3}{*}{\multicolumn{2}{|c|}{$\begin{array}{ll}\text { Nerve } & \begin{array}{c}\text { Amplitude } \\
(\mathbf{m V})\end{array} \\
\text { Right Median } & \text { NR } \\
\text { Right Radial } & \text { NR } \\
\text { Right Sural } & \text { I }\end{array}$}} & \multirow{3}{*}{$\begin{array}{l}\text { Distal } \\
\text { Latency (ms) }\end{array}$} & Right Temporalis & +++ \\
\hline & & & & & & & 1st Dorsal Interosseus & +++ \\
\hline & & & & & & & $\begin{array}{l}\text { Tibialis Anterior } \\
\text { Soleus }\end{array}$ & $\begin{array}{l}+++ \\
+++\end{array}$ \\
\hline & & & & & & & & \\
\hline Nerve & $\begin{array}{l}\text { Amplitude } \\
(\mathbf{m V})\end{array}$ & $\begin{array}{l}\text { Distal } \\
\text { Latency (ms) }\end{array}$ & $\begin{array}{l}\text { Conduction } \\
\text { Velocity }(\mathbf{m} / \mathbf{s})\end{array}$ & Nerve & $\begin{array}{l}\text { Amplitude } \\
\qquad(\mathrm{mV})\end{array}$ & $\begin{array}{l}\text { Distal } \\
\text { Latency }(\mathrm{ms})\end{array}$ & & \\
\hline Left Median & 1.4 & 3.8 & 53.0 & Left Median (III) & I) 10.9 & 2.4 & & \\
\hline Left Ulnar & 1.6 & 2.8 & 50.2 & Left Ulnar & 2.3 & 2.2 & & \\
\hline
\end{tabular}

\section{PATIENT 2}

(day 12 symptom onset)

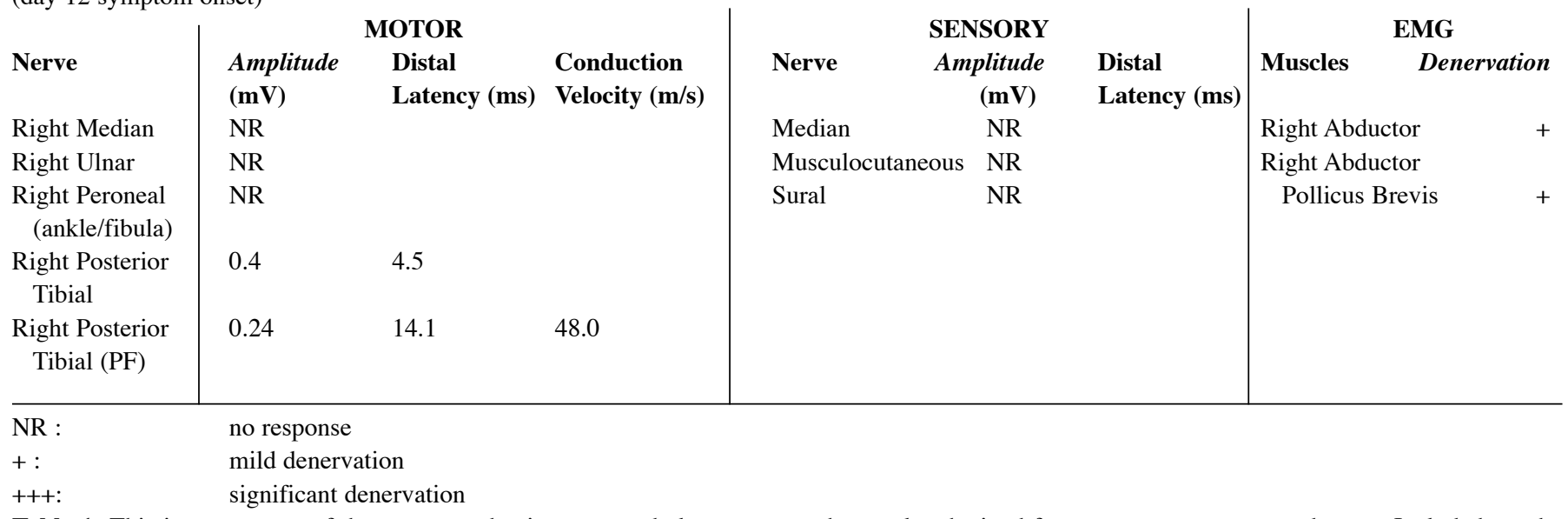

Table 1: This is a summary of the nerve conduction tests and electromyography results obtained from our own two reported cases. Included are the amplitudes and conduction velocities from various motor and sensory nerves. 
Polymerase chain reaction for herpes simplex virus was negative. On this same day, however, the patient was noted to trigger the ventilator intermittently (patient mimicked brain death for seven days). Porphyria screen and VDRL were negative. A vasculitis workup including a nasal mucosal biopsy was negative. Serum immunoelectrophoresis was normal.

On day 16, nerve conduction studies revealed that the sensory nerve action potentials in the upper limbs were absent. Evoked motor responses were of small amplitude. A sural nerve and muscle biopsy was obtained on day 17 of symptom onset (see Figure 1a-c). There was an overall decreased density of myelinated fibers. In a number of sections, macrophages occupied the axonal space surrounded by intact myelin sheaths. Active myelin breakdown was absent. Ultrastructural studies confirmed the light microscopic finding of macrophages within the adaxonal space with sparing of the myelin sheaths, but did not reveal active stripping of myelin by the macrophages. Unmyelinated fibers were relatively spared. A nerve conduction study seven weeks after presentation revealed inexcitable motor and sensory nerves (see study 1 (Patient 1) in Table 1). A sural nerve response was obtained that revealed small amplitudes but with a normal conduction velocity. These findings were consistent with the nerve biopsy findings that suggested an axonal neuropathy. Pupils became reactive on day 16 of symptom onset, followed shortly thereafter by minimal limb movements in response to pain. Recurrent pneumonia, septicemia, cardiac arrest, right occipital lobe infarction and metabolic abnormalities complicated her stormy course over the ensuing six months.

Further nerve conductions at weeks 17, 25, 36 (see study 2 (Patient 1) in Table 1) and 48 (of symptom onset) showed reduced compound motor action potentials (CMAP) with no slowing. She was transferred to the referring hospital for rehabilitation nine months following her initial admission. When the patient was reviewed at 64 weeks after the onset of her symptoms, she was cognitively intact, but recalled little of the period when she was described as being "clinically brain dead". Proximal muscle groups in the arms graded 2-3/5 (on the MRC scale) with only a flicker of movement noted in the wrist dorsiflexors. Flexion contractures had formed in the distal digits. Hip and knee flexors and ankle dorsiflexors were $3-4 / 5$. She remained hyporeflexic with mild sensory abnormalities. She also remained wheelchair bound.

\section{Patient 2}

A 27-year-old man bumped his head when roused from sleep nine days following the development of a sore throat. Later that day, he complained of double vision and developed difficulty swallowing and diffuse weakness and numbness in his limbs. Computerized tomography scans of the head and cervical spine were normal and he was transferred to a tertiary centre on day 3 of symptom onset. On examination, he was afebrile, alert and cognitively intact. A left abducens palsy was present with partial weakness of the right frontalis. There was generalized weakness, with the upper limbs most affected (grade 4 on the MRC scale). Reflexes were absent and the plantar responses were flexor. Sensory examination was normal. The weakness rapidly progressed over several hours and he required intubation. The MRI of the cervical spine and brainstem immediately obtained was normal. A lumbar puncture demonstrated a mild increase of protein at $0.58 \mathrm{~g} / \mathrm{L}$ with 8 white cells ( $70 \%$ polymorphs with $28 \%$ lymphocytes) and 12 red cells. In the ensuing hours, all brainstem reflexes including corneals, gag, oculocephalic and calorics disappeared, but he still triggered the ventilator. The next day (five days following onset of symptoms), the patient no longer triggered the ventilator and was clinically unresponsive
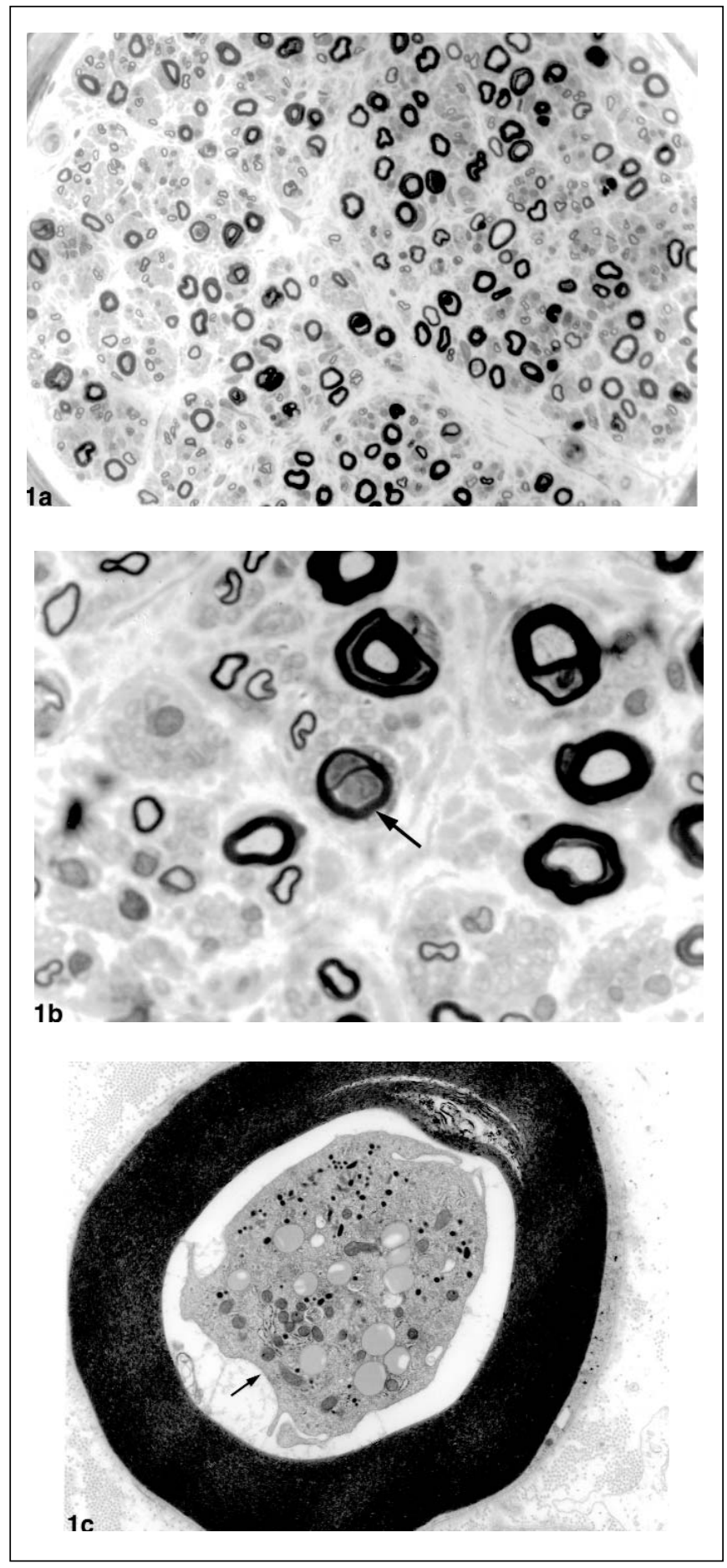

Figure 1a-c: Sections taken from the sural nerve. 1a is a low power view (magnification x600) that displays the decreased density of myelinated fibers. 1 b shows a higher magnification (x 1800) in which a cell (arrow) is seen in the space normally occupied by an axon. A lack of active inflammatory activity (myelin degradation products) is seen. $1 \mathrm{c}$ is an ultrastructural study (magnification x10,800) that depicts the presence of a macrophage within the adaxonal space with an intact myelin sheath. 
resembling the "brain dead" state. However, electroencephalography revealed a mixture of low voltage alpha waveforms distributed posteriorly, but poorly reactive. Acyclovir therapy was started. A repeat lumbar puncture (day 6 of symptom onset) revealed increased protein concentration at $1.6 \mathrm{~g} / \mathrm{L}$, but not the presence of white cells.

Screening for porphyria, vasculitis, serum immunoelectrophoresis, mycoplasma titres, HIV, as well as CSF bacterial, viral and fungal cultures were negative. A diagnosis of polyneuropathy was made and the patient received a course of intravenous gamma globulin. On day 12 of symptom onset, nerve conduction studies revealed the absence of sensory responses. Distal compound muscle action potentials could not be elicited in three of the four motor nerves assessed (Table 1). Stimulation at two sites along the right posterior tibial nerve revealed reduced CMAP but a normal conduction velocity (see Patient 2 in Table 1). Few fibrillation potentials were detected with electromyographic recordings in the several muscles examined. The findings of the electrical studies were felt to be consistent with a fulminant axonal neuropathy.

The patient remained clinically unresponsive until the 47 th day when slight ocular beating movements were noted on oculocephalic testing. Pupillary responses to light were noted five days later. The patient gradually recovered, and was weaned off the ventilator after eight months. Serial nerve conductions, however, showed electrically inexcitable nerves at 26, 47 and 70 weeks following symptom onset. At 70 weeks following symptom onset, the patient regained normal consciousness. He did not recall the period when he was clinically unresponsive. Incomplete ocular movements with features of aberrant re-innervation of facial muscles were seen. Protrusion of his tongue was limited. Proximal muscle groups in the upper limbs improved to a grade 3 level, but he had only a flicker of distal upper and lower limb movement (grade 1/5). Serology was positive for Campylobacter infection.

\section{Discussion}

These two patients suffered a severe acute paralysis leading towards an unresponsive state for which neither infective, ischemic, toxic, metabolic causes were identified. A provisional diagnosis of viral encephalitis was initially entertained in both these cases. There was rapid clinical deterioration in both cases, such that within six days of the appearance of neurological symptoms, these patients met the clinical bedside criteria for the diagnosis of brain death, although laboratory testing suggested otherwise. Subsequent nerve conduction studies confirmed the presence of a polyneuropathy with prominent axonal involvement and blocking of all outgoing (de-efferentation) activity.

In the first case, the diagnosis of central pathology (such as encephalitis) was strongly considered, as there was fever, leukocytosis, spinal fluid pleocytosis and extensor plantar responses in the first 48 hours. However, the persistently negative CSF cultures and normal MRI imaging of the brain did not support this diagnosis. Instead, subsequent investigations (spinal fluid, nerve conductions and biopsy) were in keeping with an idiopathic polyneuropathy. Initial nerve conductions and serial studies revealed small amplitudes with normal conduction velocities. This "axonal" pattern was consistent with the pathological findings, which revealed diffuse axonal loss with the frequent finding of intact myelin sheaths with intra-axonal macrophages. There was a conspicuous absence of inflammation (active breakdown of myelin) (See Figures 1a-c).

Furthermore, the ensuing course of slow and modest motor clinical recovery, in which the patient remained wheelchair bound 15 months after disease onset, is consistent with the slow recovery expected for polyneuropathy with significant axonal

Table 2a: Fulminant Polyneuropathy Simulating Brain Death in our two Reported Cases

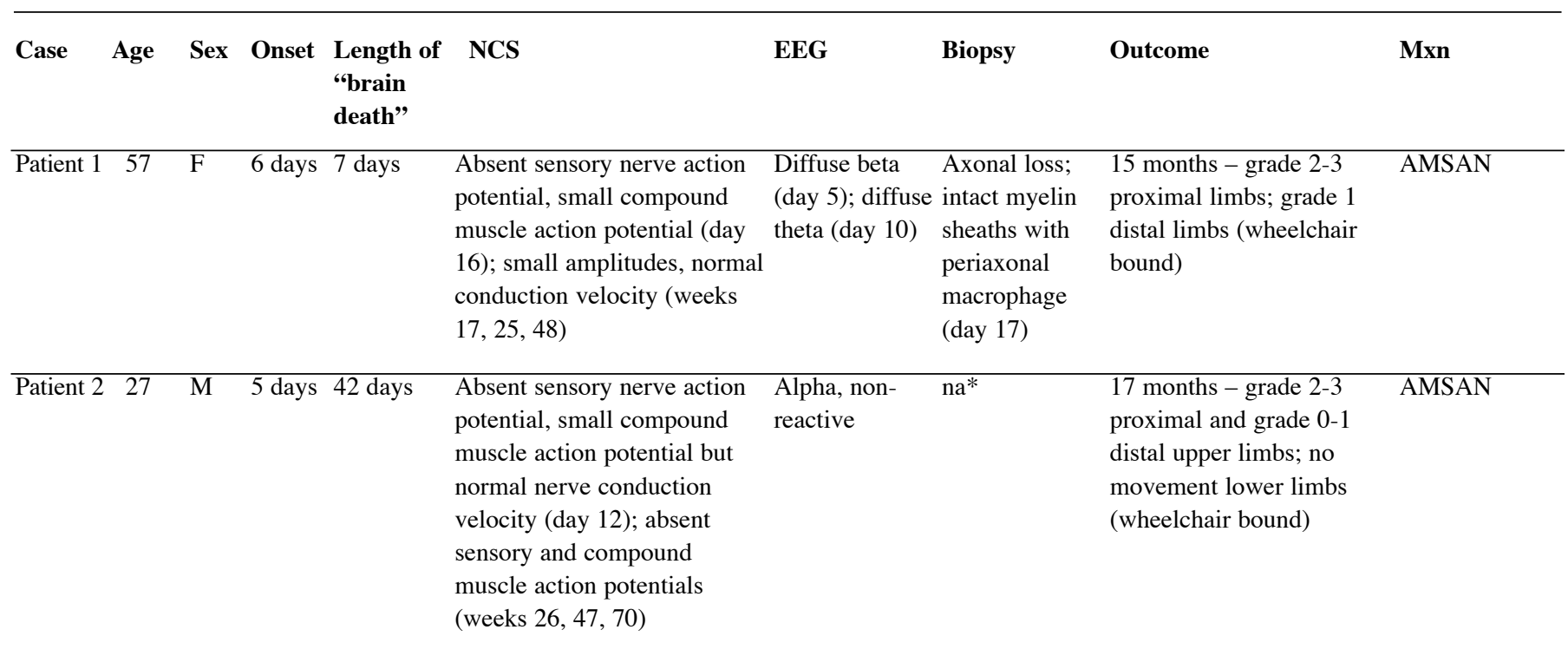

*na = not available; AMSAN = acute motor sensory axonal neuropathy; $\mathrm{Mxn}=$ proposed pathogenetic mechanism 
Table 2b: Fulminant Polyneuropathy Simulating Brain Death

\begin{tabular}{|c|c|c|c|c|c|c|c|c|}
\hline Author & Age & Sex & Onset & $\begin{array}{l}\text { Length } \\
\text { of "brain } \\
\text { death" }\end{array}$ & NCS & EEG & Biopsy & Outcome \\
\hline $\begin{array}{l}\text { Carroll et al. } \\
1979^{18}\end{array}$ & 45 & M & 6 days & 8 days & na* & $\begin{array}{l}\text { Alpha, reactive }(8 \\
\mathrm{Hz})\end{array}$ & na* & $\begin{array}{l}12 \text { months - able to walk } \\
\text { with crutches }\end{array}$ \\
\hline $\begin{array}{l}\text { Kotsoris et al. } \\
1984^{19}\end{array}$ & 44 & M & 4 days & $6 \mathrm{wks}$ & Inexcitable & $\begin{array}{l}\text { Alpha, non- } \\
\text { reactive }\end{array}$ & na* & $\begin{array}{l}6 \text { wks. - pupils reactive, } \\
12 \text { weeks - partial motor } \\
\text { recovery }\end{array}$ \\
\hline $\begin{array}{l}\text { Al-Din et al. } \\
1985^{20}\end{array}$ & 45 & $\mathrm{M}$ & 3 days & 5 days & na* & na* & na* & $\begin{array}{l}3 \text { months - full eye ocular } \\
\text { movements; profound } \\
\text { weakness }\end{array}$ \\
\hline $\begin{array}{l}\text { Drury et al. } \\
1987^{21}\end{array}$ & 63 & $\mathrm{M}$ & 36 hrs. & 46 days & $\begin{array}{l}\text { "no response" (days 5, } \\
26)\end{array}$ & Alpha, reactive & na* $^{*}$ & na* $^{*}$ \\
\hline $\begin{array}{l}\text { Kanda et al. } \\
1989^{27}\end{array}$ & 47 & $\mathrm{M}$ & 6 days & $\begin{array}{l}\text { Died on } \\
\text { day } 7\end{array}$ & $\begin{array}{l}\text { Polyphasic, smaller } \\
\text { potentials }\end{array}$ & na* & $\begin{array}{l}\text { Acute demyelin- } \\
\text { ation (autopsy) }\end{array}$ & Died on day 7 \\
\hline $\begin{array}{l}\text { Coad et al. } \\
1990^{22}\end{array}$ & 43 & $\mathrm{M}$ & 4 days & 5 days & na* & $\begin{array}{l}\text { Alpha, non- } \\
\text { reactive }\end{array}$ & na* & "full recovery" \\
\hline $\begin{array}{l}\text { Hassan et al. } \\
1991^{23}\end{array}$ & 45 & $\mathrm{M}$ & ? 3 days & $?$ & na* & Alpha, reactive & na* & $\begin{array}{l}6 \text { months ventilation; } 14 \\
\text { months - wheelchair }\end{array}$ \\
\hline $\begin{array}{l}\text { Fuller et al. } \\
1992^{26}\end{array}$ & 63 & $\mathrm{M}$ & 4 days & 7 days & $\begin{array}{l}\text { Absent sensory and } \\
\text { motor potentials (day 7) }\end{array}$ & $\begin{array}{l}\text { Alpha, non- } \\
\text { reactive }\end{array}$ & $\begin{array}{l}\text { Active demyelin- } \\
\text { ation ( } 6 \text { days of } \\
\text { onset) }\end{array}$ & $\begin{array}{l}\text { Died on day } 18 \text { from } \\
\text { arrythmia }\end{array}$ \\
\hline $\begin{array}{l}\text { Martí-Massó et al. } \\
1993^{24}\end{array}$ & 58 & $\mathrm{~F}$ & 2 days & 13 days & $\begin{array}{l}\text { "axonal damage" } \\
\text { (4 months), normal at } \\
12 \text { months }\end{array}$ & $\begin{array}{l}\text { Alpha, non- } \\
\text { reactive }\end{array}$ & na* & $\begin{array}{l}12 \text { months - able to walk } \\
\text { alone }\end{array}$ \\
\hline $\begin{array}{l}\text { Tan et al. } \\
1995^{25}\end{array}$ & 50 & $\mathrm{~F}$ & 9 days & 12 days & $\begin{array}{l}\text { Absent potentials (day 7), } \\
\text { slowed conduction (day } \\
38,97 \text { ) }\end{array}$ & $\begin{array}{l}\text { Alpha, non- } \\
\text { reactive }\end{array}$ & na* $^{*}$ & $\begin{array}{l}\text { At least grade } 4 \text { upper } \\
\text { limbs; grade } 3 \text { lower limbs } \\
\text { (day 97); died on day } 98\end{array}$ \\
\hline $\begin{array}{l}\text { Bakshi et al. } \\
1997^{31}\end{array}$ & 6 & $\mathrm{M}$ & 2 days & ? few wks & $\begin{array}{l}\text { Inexcitable nerves (day } \\
5 \text { ), low amplitude, } \\
\text { prolonged latencies }\end{array}$ & $\begin{array}{l}\text { Theta activity, } \\
\text { reactive }\end{array}$ & Demyelination & $\begin{array}{l}12 \text { months }- \text { able to } \\
\text { ambulate with assistance }\end{array}$ \\
\hline $\begin{array}{l}\text { Berciano et al. } \\
1997^{29}\end{array}$ & 67 & $\mathrm{M}$ & na* & na* & Inexcitable nerves & Reactive & Demyelination & Died on day 18 \\
\hline $\begin{array}{l}\text { Bohlega et al. } \\
1997^{28}\end{array}$ & 45 & $\mathrm{M}$ & 3 days & 31 days & $\begin{array}{l}\text { Inexcitable nerves (until } \\
5 \text { months), delayed } \\
\text { conduction }\end{array}$ & $\mathrm{na}^{*}$ & $\begin{array}{l}\text { Active demyelin- } \\
\text { ation ( } 20 \text { days), } \\
\text { axonal loss ( } 97 \\
\text { days) }\end{array}$ & $\begin{array}{l}30 \text { months - proximal limb } \\
\text { recovery, severe distal } \\
\text { weakness, sensory loss }\end{array}$ \\
\hline $\begin{array}{l}\text { Vargas et al. } \\
2000^{30}\end{array}$ & 45 & $\mathrm{~F}$ & 1 day & 8 months & na* & Alpha $(7-11 \mathrm{~Hz})$ & $\begin{array}{l}\text { Presumed axonal } \\
\text { loss secondary to } \\
\text { demyelination }\end{array}$ & $\begin{array}{l}\text { Grade } 3 \text { power upper } \\
\text { limbs, limited movement } \\
\text { of fingers; grade } 2 \text { power } \\
\text { lower limbs }\end{array}$ \\
\hline
\end{tabular}

na* = not available

Table 2a-b: 2a (previous page) is a summary of the clinical details of our own two cases. Included are the age and sex of the patient; the time of symptom onset before the presentation of the "brain death" state (Onset); the duration of "brain death"; nerve conduction studies (NCS) if available; EEG results; biopsy results if available; and the clinical outcome of these patients. 2a also includes the proposed pathogenetic mechanism (Mxn) based on combined clinical and laboratory supported data (see text). $\mathbf{2 b}$ is a compilation of the previously reported cases in which a fulminant neuropathy was giving rise to a clinical state resembling brain death. 
involvement. The CSF pleocytosis and central findings such as the extensor plantar responses remain unexplained. Possible explanations include a seizure resulting from metabolic abnormalities or an indolent infection, although thorough investigations did not reveal any abnormalities.

In Patient 2, the diagnosis of a structural lesion involving the medullary-cervical junction was considered initially. When the neuroimaging was negative, the diagnosis of encephalitis was briefly entertained because of a mild pleocytosis in the spinal fluid. A subsequent spinal fluid analysis revealed the typical "albuminocytologic dissociation". Electrophysiologic studies demonstrated a severe polyneuropathy initially characterized by small evoked response amplitudes and normal conduction velocities (Table 1). The subsequent finding of absent motor potentials on serial studies, were again most consistent with an "axonal" pattern of polyneuropathy. A nerve biopsy was not obtained as the patient's family refused such testing. Thus, a proposed "axonal" pattern can only be inferred from the electrophysiological findings. As in Patient 1, the course of clinical recovery was slow, as one would expect with the regeneration of axons. This patient remained wheelchair bound with no lower limb movements and only a flicker of movement in the distal upper limbs at 17 months after symptom onset. Table 2a summarizes the investigation results of both of these patients.

Guillain-Barré syndrome is, by definition, a monophasic disorder with a good prognosis for functional recovery if the patient can be supported through the acute paralytic phase. Although admission to an intensive care unit for ventilatory support is common, progression to a state of global deefferentation to resemble "brain death" is rare. These two patients exemplify: i) the difficulties in diagnoses of rapidlyprogressing variant forms of GBS; ii) the potential for untoward outcome if de-efferentation associated with acute polyneuropathy is not considered in the differential diagnosis of the clinically unresponsive state; and iii) the importance of electrophysiologic and paraclinical testing, especially in cases of coma where the etiology is unclear.

The pathogenesis of the polyneuropathy affecting these two patients can be postulated in light of our current understanding of the different pathogenic mechanisms in GBS and its variants. ${ }^{6,7}$

The axonal form of GBS first described by Feasby et $\mathrm{al}^{8}$ is characterized by a more severe clinical course associated with a poorer outcome. Electrophysiological findings suggestive of axonal loss include reduced CMAPs, in contrast to the demyelinating features of prolonged distal motor latency, slowing of motor nerve conduction velocity, temporal dispersion and conduction block in typical GBS. ${ }^{9,10}$ However, this electrophysiological picture could have been due to distal demyelination in intramuscular nerve twigs (leading to conduction block) and need not imply axonal loss. ${ }^{11-13}$

The concept of a primary axonal process received more support, however, when McKhann et al ${ }^{14-16}$ described an epidemic of polyneuropathy seen in northern China among younger children and adolescents in the summer months. Neurophysiological and pathological studies were not unlike those reported by Feasby and co-workers. ${ }^{8}$ Termed acute motor axonal neuropathy (AMAN) (with conspicuous absence of sensory involvement) ${ }^{15}$ similar pathological features were then reported in patients in North America, with both motor and sensory involvement otherwise referred to as acute motor and sensory neuropathy or AMSAN. ${ }^{17}$

Table 2b summarizes previous cases of "brain death" attributed to a fulminant neuropathy. Carrol and Mastaglia ${ }^{18}$ described the first case of "locked-in coma" attributable to a peripheral neuropathy, in view of the clinical findings (areflexia, profound paralysis with elevated CSF protein) and the lack of obvious abnormalities on the EEG to suggest a central cause. Neuroimaging and electrophysiological studies were not performed. Kotsoris et $\mathrm{al}^{19}$ documented inexcitable nerves in a patient who developed a rapidly ascending paralysis that resulted in a clinically "brain dead" state with loss of all brainstem reflexes and lack of any demonstrable nonautonomic neurological function, not unlike our two cases. Pupillary responses returned only six weeks later, similar to our second case. Electrophysiological studies, pathology and clinical follow-up, however, were not available to further characterize the neuropathy. Reports of four similar cases reported earlier also lack laboratory evidence to confirm the nature of the neuropathy. ${ }^{20-23}$

Electrophysiological testing was obtained in a case described by Martí-Massó et al. ${ }^{24} \mathrm{~A}$ woman lapsed into a state resembling brain death after only 48 hours of symptom onset. She remained in this state for 13 days but made progressive recovery. Nerve conductions completed four months later were described as showing "a pattern of axonal damage". Most striking were the "normal" nerve conductions at 12 months after symptom onset and that the patient was able to walk alone with only mild weakness in the limbs. The case reported by Tan and $\mathrm{Chee}^{25}$ led a similar course. Both sensory and motor potentials could not be elicited initially. Subsequent nerve conductions revealed low amplitude CMAPs with slowing that gradually improved. The authors felt that the rapid clinical recovery and electrophysiological findings were more compatible with resolution of severe distal nerve conduction block, given the rapid improvement, rather than primary axonal loss with subsequent regeneration.

Cases of "brain death" attributed to neuropathies where both electrophysiological and nerve tissue samples were available have also been reported. Fuller et $\mathrm{al}^{26}$ described a patient who lapsed into a state mimicking brain death after four days. Both sensory and motor nerves were inexcitable on conduction studies carried out seven days after symptom onset. Pathological findings from a sural nerve biopsy (taken at six days after symptom onset) were obtained, that revealed active demyelination, rather than a primary axonopathy. Others including Kanda et al, ${ }^{27}$ Bohlega et al, ${ }^{28}$ Berciano et $\mathrm{al}^{29}$ and more recent cases documented by Vargas et al, ${ }^{30}$ have reported cases with similar clinical pictures, similar electrophysiological recordings as well as similar pathological findings on biopsies and/or autopsies.

In the pediatric literature, Bakshi et $\mathrm{al}^{31}$ also described a similar fulminant picture in a six-year-old boy, who had been treated with cisplatin and etoposide. Electrophysiological studies suggested inexcitable nerves with subsequent low amplitude and prolonged distal latency responses. Sural nerve biopsy supported active demyelination, while the child made good recovery from the "clinically brain dead" state. Twelve months after symptom 
onset, he had almost normal upper extremities with the ability to walk with assistance.

Case 2 of this paper was the subject of a brief report. ${ }^{32}$ The current report permits comparison to the previous cases. In our two patients, the electrophysiological studies are admittedly limited and the pathological correlate is only available on one of the cases. However, the available serial nerve conductions, and the sural nerve biopsy in case 1 are most consistent with an "axonal pattern". These findings suggest a different pathogenesis from any of the earlier reported cases mimicking brain death, and more in keeping with those seen in the AMAN and AMSAN cases described by Griffin et al. ${ }^{17}$ This proposal of a "primary axonapathy" process is also consistent with the very slow clinical recovery. Both patients at 15-17 months from symptom onset are still non-independent and wheelchair bound. Both of our patients have recovered to grade 2-3 proximal upper limb strength and only a flicker of movement distally with evidence of contracture formation. The rapidity of clinical progression, electrophysiological findings and delayed recovery of our two cases are similar to the cases reported by Feasby et $\mathrm{al}^{33}$ from which pathological evidence was shown to suggest a primary axonopathy in cases of severe GBS.

\section{CONCLUSION}

Mimickers of brain death can include drug intoxication, brainstem ischemia, neuromuscular blockade, and hypothermia. The recognition of acquired polyneuropathy as part of the differential is important and increasingly recognized. The incidence of such cases is likely to be greater than the few cases reported, given the diagnostic difficulties in these cases, particularly if neuropathy is not considered. Indeed, the mistaken diagnosis of brain death in such cases of fulminant polyneuropathy may lead to treatment withdrawal in a reversible and arguably, treatable condition. The utility of nerve conductions is clearly required for the recognition of neuropathies and the importance of EEGs and cerebral flow scans cannot be understated in cases of unexplained coma-like states, as emphasized by many of the authors cited.

The rapidity of onset and the initial devastating neurological picture does not necessarily imply a poor prognosis requiring long term rehabilitation (as observed in our cases). Patients can recover rapidly if the underlying pathophysiological mechanism is segmental distal demyelination, ${ }^{25}$ disrupted conduction from deposition of antibodies at the nodes of Ranvier ${ }^{34}$ or distal axonal degeneration with rapid regeneration. ${ }^{35}$ These mechanisms are likely to have accounted for the previous reported cases of fulminant neuropathy. On the other hand, "axonal neuropathy" is associated with a more prolonged recovery and is the likely mechanism for the neuropathy observed in our cases. Relevant to current management is the necessity of serial EMGs and clinical assessment in the cases of fulminant polyneuropathy for prognosis. Pathological features described in the axonal forms (i.e. AMAN; AMSAN) in nerve biopsies may also be helpful.

\section{ACKNOWLEDGEMENTS}

We thank Dr. Gyl Midroni for his insightful comments and help in preparing the manuscript and Dr. Sukriti Nag for her assistance with the photomicrograph magnifications.

\section{REFERENCES}

1. Haymaker W, Kernohan JW. The Landry-Guillain-Barré syndrome. A clinicopathologic report of fifty fatal cases and a critique of the literature. Medicine (Baltimore) 1949; 28:59-141.

2. Asbury AK, Arnason BGW, Adams RD. The inflammatory lesion in idiopathic polyneuritis. Its role in pathogenesis. Medicine (Baltimore) 1969; 58:173-215

3. Prineas JW. Pathology of the Guillain-Barré syndrome. Ann Neurol 1981; 9(Suppl):6-19.

4. Ng KKP, Howard RS, Fish DR, et al. Management and outcome of severe Guillain-Barré syndrome. QJ Med 1995; 88:243-250.

5. Lawn ND, Wijdicks EF. Fatal Guillain-Barré syndrome. Neurol 1999; 52:635.

6. Thomas PK. The Guillain-Barré syndrome: no longer a simple concept. J Neurol 1992; 239:361-362.

7. Bolton CF. The changing concepts of Guillain-Barré Syndrome. N Engl J Med 1995; 333:1415-1416.

8. Feasby TE, Gilbert JJ, Brown WF, et al. An acute axonal form of Guillain-Barré polyneuropathy. Brain 1986; 109:1115-1126.

9. McLeod JG. Electrophysiological studies in the Guillain-Barré syndrome. Ann Neurol 1981; 9:20-27.

10. Brown WF, Feasby TE. Conduction block and denervation in Guillain-Barré polyneuropathy. Brain 1984; 107:219-239.

11. Brown WF, Snow R. Patterns and severity of conduction abnormalities in Guillain-Barré syndrome. J Neurol Neurosurg Psychiatry 1991; 54:768-774.

12. Hall SM, Hughes RAC, Atkinson PF, McColl I, Gale A. Motor nerve biopsy in severe Guillain-Barré syndrome. Ann Neurol 1992; 31:441-444.

13. Cros D, Triggs WJ. There are no neurophysiologic features characteristic of "axonal" Guillain-Barré syndrome. Muscle Nerve 1994; 17:675-677.

14. McKhann GM, Cornblath DR, Ho T, et al. Clinical and electrophysiological aspects of acute paralytic disease in children and young adults in northern China. Lancet 1991; 338:593-597.

15. McKhann GM, Cornblath DR, Griffin JW, et al. Acute motor axonal neuropathy: a frequent cause of acute flaccid paralysis in China. Ann Neurol 1993; 33:333-342.

16. Griffin JW, Li CY, Ho TW et al. Guillain-Barré syndrome in northern China: the spectrum of neuropathologic changes in clinically defined cases. Brain 1995; 118:577-595.

17. Griffin JW, Li CY, Ho TW, et al. Pathology of the motor-sensory axonal Guillain-Barré syndrome. Ann Neurol 1996; 39:17-28

18. Carroll WM, Mastaglia FL. "Locked-in coma" in postinfectious polyneuropathy. Arch Neurol 1979; 36:46-47.

19. Kotsoris H, Schleifer L, Menken M, Plum F. Total locked-in state resembling brain death in polyneuropathy. Ann Neurol 1984; 16:150.

20. Al-Din ASN, Jamil, AS, Shakir R. Coma and brains stem areflexia in brain stem encephalitis (Fisher's syndrome). Br Med J 1985; 291:535-536.

21. Drury I, Westmoreland BF, Sharbrough FW. Fulminant demyelinating polyradiculoneuropathy resembling brain death. Electroencephalogr Clin Neurophysiol 1987; 67:42-43.

22. Coad NR, Byren AJ. Guillain-Barré syndrome mimicking brainstem death. Anaesthesia 1990; 45:456-457.

23. Hassan T, Mumford C. Guillain-Barré syndrome mistaken for brain stem death. Postgrad Med J 1991; 67:280-281.

24. Martí-Massó JF, Suárez J, López de Munain A, Carrera N. Clinical signs of brain death simulated by Guillain-Barré syndrome. J Neurol Sci 1993; 120:115-117.

25. Tan AKY, Chee MWL. Fulminant Guillain-Barré syndrome with quadriplegia and total paresis of motor cranial nerves as a result of segmental demyelination. J Neurol Sci 1995; 134:203-206.

26. Fuller GN, Jacobs JM, Lewis PD, Lane RJM. Pseudoaxonal Guillain-Barré syndrome: severe demyelination mimicking axonopathy. A case with pupillary involvement. J Neurol Neurosurg Psychiatry 1992; 55:1079-1083.

27. Kanda T, Hayashi H, Tanabe H, Tsubaki T, Oda M. A fulminant case of Guillain-Barré syndrome: topographic and fibre size related 
analysis of demyelinating changes. J Neurosurg Psychiatry 1989; 52:857-864.

28. Bohlega SA, Stigsby B, Haider A, et al. Guillain-Barré syndrome with severe demyelination mimicking axonopathy. Muscle Nerve 1997; 20:514-516.

29. Berciano J, Figols J, Garcia A, et al. Fulminant Guillain-Barre syndrome with universal inexcitability of peripheral nerves: a clinicopathological study. Muscle Nerve 1997; 20:846-857.

30. Vargas F, Hilbert G, Gruson D, et al. Fulminant Guillain-Barre syndrome mimicking cerebral death: case report and literature review. Intensive Care Med 2000; 26:623-627.

31. Bakshi N, Maselli R, Gospe SM, et al. Fulminant demyelinating neuropathy mimicking cerebral death. Muscle Nerve 1997; 20:1595-1597.
32. Hughes R, McGuire G. Neurological disease and the determination of brain death: the importance of a diagnosis. Crit Care Med 1997; 25: 1923-1924.

33. Feasby TE, Hahn AF, Brown WF, et al. Severe axonal degeneration in acute Guillain-Barre syndrome: evidence of two different mechanisms? J Neurol Sci 1993;116: 185-192.

34. Ho TW, Li CY, Cornblath DR, et al. Patterns of recovery in the Guillain-Barre syndromes. Neurology 1997a; 48:695-700.

35. Ho TW, Hsieh S-T, Nachamkin I, et al. Motor nerve terminal degeneration provides a potential mechanism for rapid recovery in acute motor axonal neuropathy after Campylobacter infection. Neurology 1997b; 48:717-724. 